\title{
STUDY ON THE AVAILABILITY OF COMMERCIAL SOFTWARE FOR THE CORPS' LIFE CYCLE PROJECT MANAGEMENT (LCPM)
}

\author{
by
}

N. Radhakrishnan, Bobby Hughey, Warren Bennett Information Technology Laboratory

DEPARTMENT OF THE ARMY

Waterways Experiment Station, Corps of Engineers PO Box 631, Vicksburg, Mississippi 39181-0631
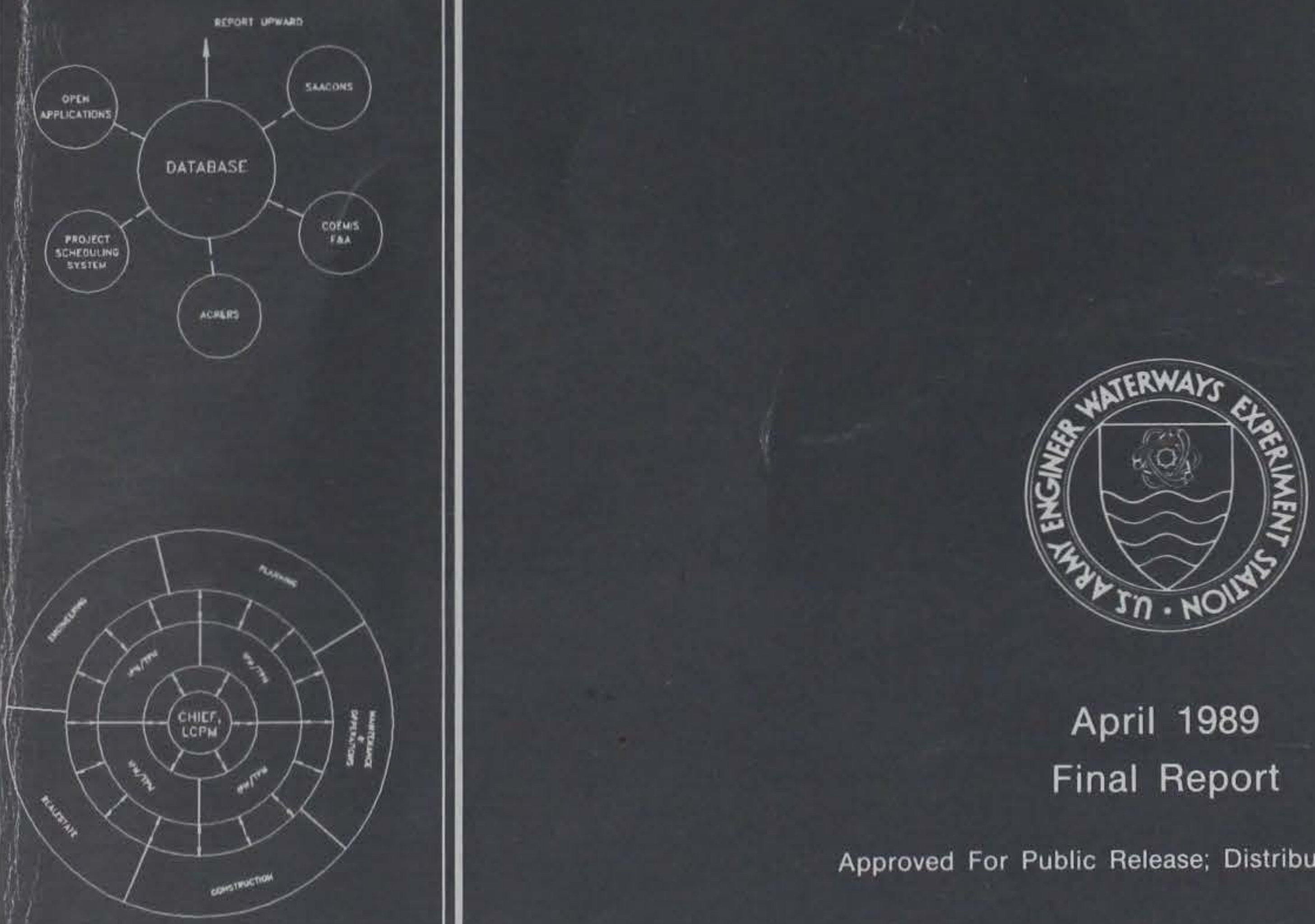

April 1989

Final Report

Approved For Public Release; Distribution Unlimited

Prepared for DEPARTMENT OF THE ARMY

US Army Corps of Engineers

Washington, DC 20314-1000 
Unclassified

SECURITY CLASSIFICATION OF THIS PAGE

\section{REPORT DOCUMENTATION PAGE}

\begin{tabular}{|c|c|c|c|c|}
\hline \multicolumn{2}{|l|}{$\begin{array}{l}\text { 1a. REPORT SECURITY CLASSIFICATION } \\
\text { Unclassified }\end{array}$} & \multicolumn{3}{|l|}{ 16. RESTRICTIVE MARKINGS } \\
\hline \multicolumn{2}{|c|}{ 2a. SECURITY CLASSIFICATION AUTHORITY } & \multicolumn{3}{|c|}{$\begin{array}{l}\text { 3. DISTRIBUTION/AVAILABILITY OF REPORT } \\
\text { Approved for public release; distribution unlimited. }\end{array}$} \\
\hline $\begin{array}{l}\text { 4. PERFORMING ORGANIZATION REPORT NUI } \\
\text { Technical RepOrt ITL-89-2 }\end{array}$ & $\overline{R(S)}$ & \multicolumn{3}{|c|}{ 5. MONITORING ORGANIZATION REPORT NUMBER(S) } \\
\hline $\begin{array}{l}\text { 6a. NAME OF PERFORMING ORGANIZATION } \\
\text { USAEWES, Information } \\
\text { Technology Laboratory }\end{array}$ & $\begin{array}{l}\text { 6b. OFFICE SYMBOL } \\
\text { (If applicable) } \\
\text { CEWES-IM-Z }\end{array}$ & \multicolumn{3}{|c|}{ 7a. NAME OF MONITORING ORGANIZATION } \\
\hline $\begin{array}{l}\text { 6c. ADDRESS (City, State, and ZIP Code) } \\
\text { PO Box } 631\end{array}$ & Vicksburg, MS 39181-0631 & \multicolumn{3}{|c|}{ 7b. ADDRESS (City, State, and ZIP Code) } \\
\hline $\begin{array}{l}\text { 8a. NAME OF FUNDING ISPONSORING } \\
\text { ORGANIZATION } \\
\text { US Army COrps of Engineers }\end{array}$ & $\begin{array}{l}\text { 8b. OFFICE SYMBOL } \\
\text { (If applicable) }\end{array}$ & \multicolumn{3}{|c|}{ 9. PROCUREMENT INSTRUMENT IDENTIFICATION NUMBER } \\
\hline \multicolumn{2}{|l|}{ 8c. ADDRESS (City, State, and ZIP Code) } & \multicolumn{3}{|c|}{ 10. SOURCE OF FUNDING NUMBERS } \\
\hline \multicolumn{2}{|l|}{ Washington, DC 20314-1000 } & $\begin{array}{l}\text { PROGRAM } \\
\text { ELEMENT NO. }\end{array}$ & $\begin{array}{l}\text { TASK } \\
\text { NO. }\end{array}$ & $\begin{array}{l}\text { WORK UNIT } \\
\text { ACCESSION NO. }\end{array}$ \\
\hline
\end{tabular}

11. TITLE (Include Securrity Classification)

Study on the Availability of Commercial Software for the Corps' Life Cycle Project Management (LCPM)

12. PERSONAL AUTHOR(S)

Radhakrishnan, N.: Hughey, Bobby: Bennett, Warren

Final report

136. TIME COVERED
FROM Jan 89 TO Mar 89

14. DATE OF REPORT (Year, Month, Day) 15. PAGE COUNT April 1989 68

16. SUPPLEMENTARY NOTATION

Available from National Technical Information Service, 5285 Port Royal Road, Springfield, VA 22161.

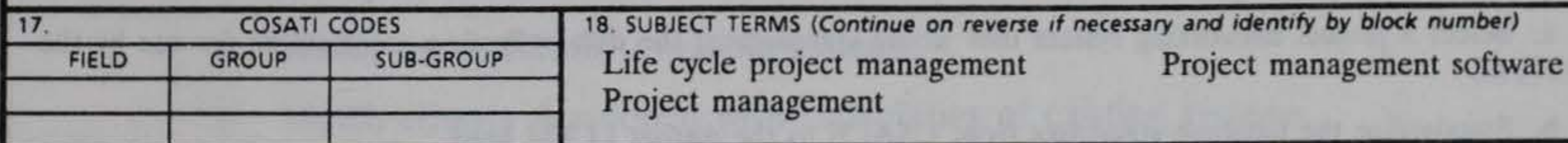

19. ABSTRACT (Continue on reverse if necessary and identify by block number)

With the advent of the Water Resources Development Act of 1989, The Corps entered into a new era in cost sharing and project management. The Corps embarked on the life cycle management of its projects and the need to report the status of its activities under a management effort entitled "Initiative 88." In recognition of the fact that current project management tools are not adequate to provide the needed information in the proper form within the prescribed time frame, the Corps is modernizing its computer-aided project management information capabilities.

The effort reported herein explores whether commercially available software can be used to meet the Corps' immediate and long-term needs, lists the criteria used in evaluating the software, gives impressions of the studied software, and gives recommendations for implementation. The primary objective was not to recommend a system(s) that would meet the Corps' needs, but to conclude only whether or not any candidate system(s) exists.

(Continued)

\begin{tabular}{|c|c|c|c|}
\hline $\begin{array}{l}\text { 20. DISTRIBUTION/AVAILABILITY OF ABSTRACT } \\
\text { XUNCLASSIFIED/UNLIMITED } \square \text { SAME AS RPT. }\end{array}$ & $\square$ DTIC USERS & $\begin{array}{l}\text { 21. ABSTRACT SECURITY CLASSIFICAT } \\
\text { Unclassified }\end{array}$ & \\
\hline 22a. NAME OF RESPONSIBLE INDIVIDUAL & & 22b TELEPHONE (Inciude Area Code) & 22C. OFFICE SYMBOL \\
\hline \multirow[t]{2}{*}{ DD Form 1473, JUN 86} & \multirow{2}{*}{\multicolumn{2}{|c|}{ Previous editions are obsolete. }} & SECURITY CLASSIFICATION OF THIS PAGE \\
\hline & & & Unclassified \\
\hline
\end{tabular}




\section{Unclassified}

19. ABSTRACT (Continued).

The approach used was:

a. Survey available information and previous studies.

b. Define the requirements and establish criteria.

c. Survey commercially available systems.

d. Match criteria developed with capabilities of existing systems.

e. Recommend solutions.

The study was conducted using a field task group approach to bring balance and realism to the conclusions and recommendations.

The task group addressed three requirements in developing the criteria. These are: scheduling and reporting requirements mandated with the implementation of Life Cycle Project Management (LCPM), scheduling and reporting requirements currently mandated by the Corps, and internal field operating agency (FOA) management scheduling and reporting needs. They concluded that project management system software that will meet the requirements should consist of a project scheduling component and a project control component with appropriate capabilities in networking, reporting, resource handling, and interfacing. They selected six products as candidates for review and visited the vendor facilities.

Conclusions are provided below:

a. Software products exist in the commercial market that could be used to satisfy LCPM at all levels of management.

b. LCPM requirements at the District, Division, and HQUSACE levels can be satisfied by providing report extracts from the IPM/TPM micro systems.

c. A micro-based project management system consisting of a project scheduler and a DBMS must be identified as part of a recommended system to be used by the IPM/TPM.

Recommendations are provided below:

a. Select a project networking system that would complement the data collection requirement for use by the IPM/TPM.

b. Standardize the database structures from USACE to the district LCPM level.

c. Develop a standard work break down structure (WBS) and an organizational break down structure (OBS).

d. Acquire (or continue developing) a new F\&A system that meets the needs of not only the Comptroller but also managers of projects and resources.

e. Establish a Center for Computer-Aided Project Management (CCAPM) in the Corps similar to the ComputerAided Design and Drafting (CADD) Center at the Waterways Experiment Station. The Center, like the CADD Center, should be field-driven and should become the focal point for fostering project management activities in the Corps. The Center will be a facilitator for the HQ Program Manager for LCPM.

f. During CEAP pilot testing consider the impact of CEAP and the redesigned F\&A system on the recommendations.

g. An implementation strategy using commercially available software and an interfaced approach is recommended. Under this strategy data at all levels of management will be kept at a manageable level. The definition of data required for management at HQUSACE must be defined first so that subordinate offices can define their data requirements. 


\section{EXECUTIVE SUMMARY}

With the advent of the Water Resources Development Act of 1989, the Corps entered into a new era in cost sharing and project management. The Corps embarked on the life cycle management of its projects and the need to report the status of its activities under a management effort entitled "Initiative 88." In recognition of the fact that current project management tools are not adequate to provide the needed information in the proper form within the prescribed time frame, the Corps is modernizing its computer-aided project management information capabilities.

The effort reported herein explores whether commercially available software can be used to meet the Corps' immediate and long-term needs, lists the criteria used in evaluating the software, gives impressions of the studied software, and gives recommendations for implementation. The primary objective was not to recommend a system(s) that would meet the Corps' needs, but to conclude only whether or not any candidate system(s) exists.

The approach used was:

a. Survey available information and previous studies.

b. Define the requirements and establish criteria.

c. Survey commercially available systems.

d. Match criteria developed with capabilities of existing systems.

e. Recommend solutions.

The study was conducted using a field task group approach to bring balance and realism to the conclusions and recommendations.

The task group addressed three requirements in developing the criteria. These are: scheduling and reporting requirements mandated with the implementation of Life Cycle Project Management (LCPM), scheduling and reporting requirements currently mandated by the Corps, and internal field operating agency (FOA) management scheduling and reporting needs. They concluded that project management system software that will meet the requirements should consist of a project scheduling component and a project control component with appropriate 
capabilities in networking, reporting, resource handling, and interfacing. They selected six products as candidates for review and visited the vendor facilities.

Conclusions and recommendations are provided below:

\section{Conclusions}

a. Software products exist in the commercial market that could be used to satisfy LCPM at all levels of management.

b. LCPM requirements at the District, Division, and HQUSACE levels can be satisfied by providing report extracts from the IPM/TPM micro systems.

c. A micro-based project management system consisting of a project scheduler and a DBMS must be identified as part of a recommended system to be used by the IPM/TPM.

\section{Recommendations}

a. Select a project networking system that would complement the data collection requirement for use by the IPM/TPM.

b. Standardize the database structures from USACE to the district LCPM level.

c. Develop a standard work break down structure (WBS) and an organizational break down structure (OBS).

d. Acquire (or continue developing) a new F\&A system that meets the needs of not only the Comptroller but also managers of projects and resources.

e. Establish a Center for Computer-Aided Project Management (CCAPM) in the Corps similar to the Computer-Aided Design and Drafting (CADD) Center at the Waterways Experiment Station. The Center, like the CADD Center, should be field-driven and should become the focal point for fostering project management activities in the Corps. The Center will be a facilitator for the HQ Program Manager for LCPM. 
f. During CEAP pilot testing consider the impact of CEAP and the redesigned F\&A system on the recommendations.

g. An implementation strategy using commercially available software and an interfaced approach is recommended. Under this strategy data at all levels of management will be kept at a manageable level. The definition of data required for management at HQUSACE must be defined first so that subordinate offices can define their data requirements. 


\section{PREFACE}

This report investigates the availability of commercial software for the Corps of Engineers' Life Cycle Project Management (LCPM). The tasking was from Mr. John Wallace, Chief, Resource Management Office, and a member of the Headquarters Information Resource Management Executive Committee, to Dr. N. Radhakrishnan, Chief, Information Technology Laboratory (ITL), US Army Engineer Waterways Experiment Station (USAEWES). The work was performed from 15 Jan 1989 through 31 Mar 1989.

Dr. N. Radhakrishnan was Project Manager for the task. Mr. Warren Bennett, USAEWES, served as the Project Coordinator and Leader. The study was conducted using a field task group approach with Mr. Bob Hughey, Chief, Design Branch, serving as Chairman of the task group. The following members constituted the task group:
Mr. Bob Hughey, CELMS-ED-D, Chairman
Dr. Ed Middleton, CEWES-IM-D, Co-Chairman
Dr. N. Radhakrishnan, CEWES-IM-Z, Project Manager
Mr. Warren Bennett, CEWES-IM-CD-C, Project Coordinator
Mr. Darrell Alverson, CESWD-ED
Mr. James Goering, CEMRK-ED
Mr. Moon-Yong Han, CENPD-EN
Mr. Rodney Metzger, CEEC-CA
Mr. Jack Neimi, CELMS-DP
CPT Richard Thompson, CENCC-CO-A

Assistance of the task group members is gratefully acknowledged.

An In-Progress Review was provided to the Executive Committee in March 1989. Dr. Radhakrishnan, Mr. Bennett, Mr. Hughey, Mr. Metzer, and 
CPT Thompson visited the vendor sites, 7-10 March, to view the products. This report was written by Dr. Radhakrishnan, Mr. Bennett, and Mr. Hughey.

During the course of this study, the team talked with a number of people in Corps offices and outside the Corps. Particular thanks are due to Messrs. Bob Thomas and David Pence, Engineer Automation Support Agency, Ms. Bobbi Schwendig and staff, Idaho National Engineering Laboratory, and Messrs. William Moore and Jeffrey Hawkins, Logistics Management Institute. The support extended by Mr. Wallace and COL Patrick Kenny, Director of Information Management, is gratefully acknowledged. Ms. Jamie Leach, ITL, edited this document; Mses. Sandy Lewis, Martha Pettway, Linda McGowan, and Janet Kelley typed this document. Their assistance under tight time constraints is greatly appreciated.

The work was done in the period January-March 1989. Commander and Director at WES was COL Dwayne G. Lee, EN, and Technical Director was Dr. Robert W. Whalin. 


\section{CONTENTS}

EXECUTIVE SUMMARY $\ldots \ldots \ldots \ldots \ldots \ldots \ldots \ldots \ldots \ldots \ldots \ldots \ldots$ i

PREFACE $\ldots \ldots \ldots \ldots \ldots \ldots \ldots \ldots \ldots \ldots \ldots \ldots \ldots \ldots \ldots$

I. Introduction $\ldots \ldots \ldots \ldots \ldots \ldots \ldots \ldots \ldots \ldots \ldots \ldots \ldots \ldots \ldots \ldots$

II. Scope and Objectives $\ldots \ldots \ldots \ldots \ldots \ldots \ldots \ldots \ldots \ldots \ldots \ldots \ldots \ldots$

III. Study Approach $\ldots \ldots \ldots \ldots \ldots \ldots \ldots \ldots \ldots \ldots \ldots \ldots \ldots \ldots \ldots \ldots$

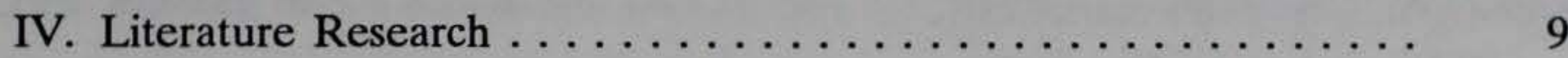

V. Criteria Development $\ldots \ldots \ldots \ldots \ldots \ldots \ldots \ldots \ldots \ldots \ldots \ldots \ldots$

Construction Management by the Corps of Engineers ....... 11

General Requirements .................... 11

District Internal Project Management Criteria . . . . . . . . 12

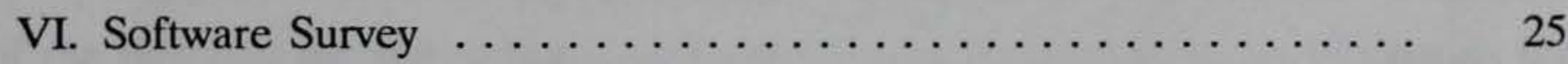

VII. Findings $\ldots \ldots \ldots \ldots \ldots \ldots \ldots \ldots \ldots \ldots \ldots \ldots \ldots \ldots \ldots \ldots \ldots \ldots \ldots \ldots$

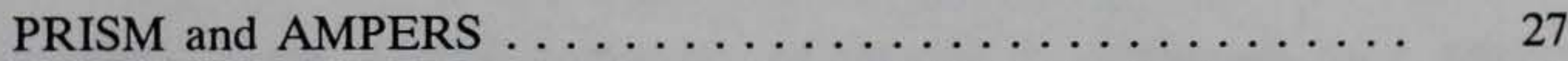

Information Systems Modernization Plan (ISMP) Emphasis . . . . 28

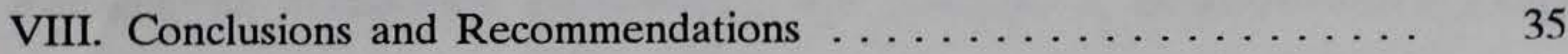

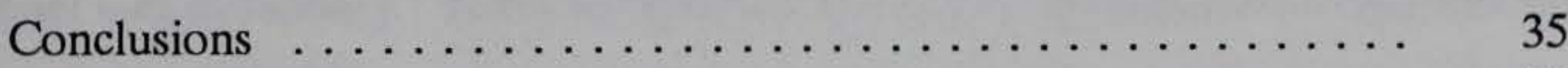

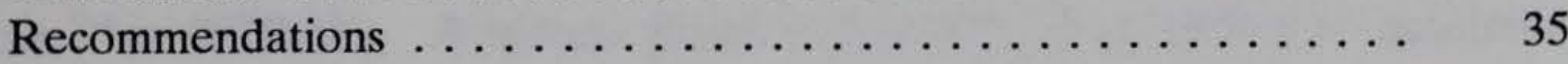

Appendix A - Definitions $\ldots \ldots \ldots \ldots \ldots \ldots \ldots \ldots \ldots \ldots \ldots \ldots \ldots \ldots \ldots \ldots$

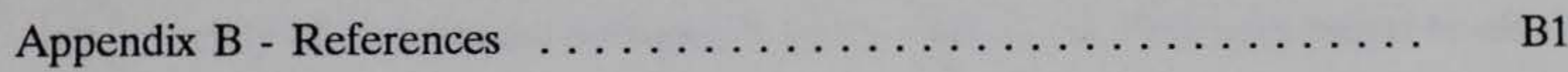

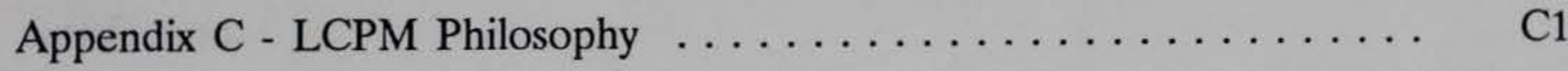

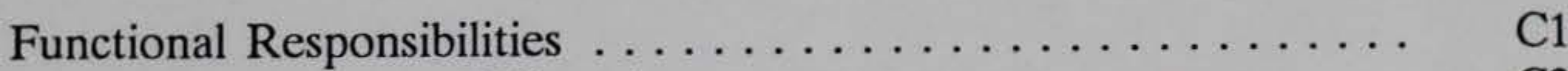

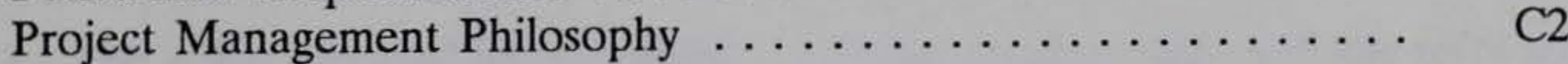

Appendix D - List of Project Management Systems Considered ..... . D1

Appendix E - Demonstration Scenario Provided to Vendors ...... E1

Appendix F - Summary Software Reviews $\ldots \ldots \ldots \ldots \ldots \ldots \ldots \ldots$ F1 


\section{Study on the Availability of Commercial Software for the Corps' Life Cycle Project Management (LCPM)}

\section{Introduction}

1. With the advent of the Water Resources Development Act of 1989, the Corps entered into a new era in cost sharing and project management. The Corps embarked on the life cycle management of its projects and reporting the status of its activities under a management effort entitled "Initiative 88." The reporting requirements of both Initiative 88 and other mandatory data items the Corps needs to accomplish its work are detailed in EC 1110-2-536 (30 Jun 88). In recognition of the fact that the old project management tools are not adequate to provide the needed information in the proper form within the prescribed time frame, the Corps is proceeding along several fronts to modernize its computer-aided project management information capabilities. For example, a group of senior Corps personnel met in January - February 1989 and developed a Structured Requirements Analysis Plan (STRAP). A second group surveyed the field offices to determine what software is currently being used in support of the LCPM. This survey found that a variety of commercial software is being used in the field with mixed levels of satisfaction.

2. The effort reported herein explores whether commercially available software can be used to meet the Corps' immediate and long-term LCPM needs. The task was assigned by Mr. John Wallace, Chief, RMO, HQUSACE, and a member of the Corps' IRM Steering Committee, to Dr. N. Radhakrishnan, Chief, Information Technology Laboratory, USAEWES, in mid-December 1988. A team of Corps personnel under the leadership of Bob Hughey, St. Louis District, assisted in developing the necessary criteria and evaluating commercially available software. 
3. This report contains criteria used in evaluating the software, impressions of the studied software, recommendations for implementation of LCPM, and some field views on operation of LCPM. A list of definitions of terms used in this report is provided in Appendix A. 


\section{Scope and Objectives}

4. The principal objective of this study was to determine whether any commercial software system(s) is (are) available that would meet most, if not all, of the Corps' needs for LCPM. LCPM, as defined in EC 1110-2-536 (30 Jun 88), is the reference criteria for this study. Additional information was acquired throughout the study from Corps personnel. As defined in the EC, LCPM begins with the assignment of a project manager and continues to the end of the Corps' interest in the project.

5. Further objectives of this study were: (a) if there is (are) commercial systems available, can they be used off-the-shelf, or do they need to be modified to fit the Corps' needs, and (b) if there are no commercial systems available, what is so unique about the Corps' requirements in comparison with the private sector requirements? It should be emphasized that the primary objective was not to recommend a system(s) that would meet the Corps' needs, but to conclude only whether or not any candidate system(s) exist.

6. Although the original task included field testing of a software package, this requirement was eliminated due to time limitations and procurement considerations. The field testing would have added very little to the study and would have been difficult to perform within the time constraints (less than 75 days). Realistic field testing would have necessitated the simulation of a life cycle of a project, training of project engineers and managers on the software, implementation of the system with interfaces to several existing Corps stove-pipe systems, and performance of other time-consuming tasks. Instead, vendor demonstration of products based on a scenario worked out by the task group was substituted for field testing. These demos were attended by engineers who were representatives of end users, middle level managers, and other raw data providers to the LCPM system. 


\section{Study Approach}

7. The approach used in this study to achieve the objectives consisted of the following steps:

a. Survey information and studies available in the Corps and elsewhere on LCPM.

b. Define requirements and establish broad functional and technical criteria.

c. Survey commercial systems available in the market.

d. Match criteria developed in (a) with capabilities of systems and develop a short list of systems:

(i) Develop a scenario for vendors to demonstrate their systems and observe the systems in action.

(ii) Augment the demos with experience from people who have used these systems.

e. Conclude and recommend solutions for both the interim as well as the long-term needs of the Corps.

8. The study was conducted using a field task group approach to bring balance and realism to the conclusions and recommendations.

9. An overview of this approach is provided below:

a. Survey Information and Studies Available in the Corps and Elsewhere on LCPM - The team reviewed a number of studies and literature available in publications and vendor provided bulletins. Studies included those by LMVD, NCD, SAM, SPS, EASA, CERL, and NASA in addition to HQ provided information such as EC 1110-2-536, Private Sector Study, LCPM STRAP, etc.

b. Broad Criteria Development - There were no published criteria available for performing LCPM in an operational environment in a district office. The criteria had to be defined before the researchers could embark on finding a 
commercial system to meet the Corps' needs. Mr. Bob Hughey, Chief, Design Branch, St. Louis District, served as chairman of the following group tasked to develop the criteria:

\author{
Mr. Bob Hughey, CELMS-ED-D, Chairman \\ Dr. Ed Middleton, CEWES-IM-D, Co-Chairman \\ Mr. Darrell Alverson, CESWD-ED \\ Mr. Warren Bennett, CEWES-IM-CD-C, Project Coordinator \\ Mr. James Goering, CEMRK-ED \\ Mr. Moon-Yong Han, CENPD-EN \\ Mr. Rodney Metzger, CEEC-CA \\ Mr. Jack Neimi, CELMS-DP \\ CPT Richard Thompson, CENCC-CO-A \\ Dr. N. Radhakrishnan, CEWES-IM-Z, Project Manager
}

The task group was formed with the belief that, for a system to be successfully fielded, "end users" of the system and middle level managers must play a strong role in defining the criteria for both upward reporting and local project management. Since engineers from district offices will be the primary contributors of data to a LCPM system, they should be involved in defining the criteria. The emphasis was on developing broad criteria in contrast to a STRAP process (which is more detailed with the development of data models). Since the study concentrated only on ascertaining the feasibility of using commercial products, this scope was deemed appropriate.

c. Survey Commercial Systems Available in the Market - There are over 150 project management software packages available on the market. Many of them run only on microcomputers. The task group predominantly looked at systems that run on a range of platforms including microcomputers, minicomputers, and mainframes. This reduced the list considerably.

d. Matching Criteria and Capabilities - The team compared the capabilities of the "short list" systems against the criteria established. A scenario was developed 
for the vendors to use during their demonstration sessions. Further, the experience that Corps FOAs had in using some of these systems was also taken into account. Six vendors were visited by a select subgroup of the task group.

e. Conclusions and Recommendations - Findings, conclusions, and recommendations were determined by carefully analyzing the results and applying a set of assumptions regarding the Corps' present and projected hardware and software environments. 


\section{Literature Research}

10. Recent research efforts to develop criteria for project management systems revealed several applicable studies. A study by NASA completed in September 1988 was of particular interest. The NASA Stennis Space Center was in need of a Construction Management Information System and contracted with Battelle Corporation to perform the study. Criteria were developed, and systems surveys were performed. This is very similar to the approach taken in the present study. The Corps task group reviewed the NASA study prior to developing the functional criteria.

11. The "Life Cycle Project Management Off-the-Shelf Software Survey" published by D/IM, 2 February 1989, itemized the efforts in the Corps to satisfy LCPM with available software and resources. The implementations varied from district to district but all attempted to derive a toolbox for the LCPM Individual Project Manager (IPM)/Team Project Manager (TPM) that satisfied the total requirement to varying extents.

12. EC 1110-2-536 and the LCPM STRAP report provided the total LCPM direction and the HQ viewpoint of LCPM. The task group was thoroughly familiar with the EC prior to convening.

13. Additional publications and journals were reviewed to obtain the industry and theoretical perspective. These included reports from CERL, the Private Sector Council study, books on project management by Kerzner and Moder, and articles from technical publications. A complete list of references is provided in Appendix B. 


\section{v. Criteria Development}

\section{Construction Management by the Corps of Engineers}

14. The Corps of Engineers administers construction contracts. The Corps does not bid, prepare detailed construction schedules, or perform the actual construction work. The Corps is an engineering organization that performs Title II services which include supervision, administration, and minimal inspection of work performed by a contractor. While the owner is often the Corps, with the Corps operating and maintaining the facility, it is becoming more and more common to have a local sponsor or another agency owner. The Corps' objective is to design a quality and innovative product, on schedule, and within budget that results in a totally satisfied customer.

\section{General Requirements}

15. In order to define the LCPM automated information criteria, the task group had to address three requirements. In order of priority these are the scheduling and reporting requirements mandated with the implementation of LCPM (see Table V.1), the scheduling and reporting requirements currently in existence mandated by the Corps (see Table V.2), and, finally, the scheduling and reporting needs of management internal in an FOA that are essential to the execution of the work (see Table V.3). The first two areas clearly require a database management capability to generate the desired information and to create the reports that the executive level of the district must submit as upward reporting to higher authority. The third area, dealing with the production level of the organization, must focus on detailed project scheduling for meeting the internal needs of management to execute the work even though complementary reporting systems are also needed. The decentralized nature of the FOAs and their individual local capabilities encourage allowing the project execution requirements internal to the FOA to be achieved using a detailed scheduling tool that is either provided in a "preferred" system or 
acquired locally. In reality, both the executive and production levels need a project management system that has project scheduling and project reporting components.

16. The philosophical underpinning for the approach is that there are some universal reports (information) that every FOA must provide. The format for providing these reports is specified, and these reports are mandatory. The detailed project management needs internal to the FOA may be considered somewhat universal but neither the content of the gathered information nor the format for presenting the material is mandated. In other words, the FOA has considerable flexibility in satisfying the detailed needs. To some it is desirable that the total needs be satisfied with the same system and that the Corps LCPM needs at both the executive and production levels be met with a commercial software. Even if such a package can be obtained, it is likely that some FOAs will prefer using their own system to meet all or a portion of the detailed project management needs. The task group feels that as long as the detailed system will provide the information needed in the format required, the FOA should be free to use the system of their choice.

\section{District Internal Project Management Criteria}

17. An FOAs daily information needs are many, and the users are diverse. First-line supervisors need detailed information on the status of their projects in terms of both finances and timeliness. They must have the ability to plan and schedule down to the individual with detailed tasks and sub-tasks, all of which must be tracked, plus obtain the feedback necessary to evaluate how the work is progressing. Branch Chiefs and Division Chiefs have increasingly broader levels of information needs while the LCPM must view their projects from a district perspective. The general requirements that the Project Management System software should satisfy are listed below, and the detailed criteria are provided in Table V.3. The levels of importance begin at 1 to indicate the feature is critical to the success of LCPM implementation and general FOA project management. The levels decrease to 4 which indicates the feature is important enough to mention but would not impact the success or LCPM or general project management. 
18. A Project Management System software that will meet the requirements of the Corps of Engineers should consist of two components: a project scheduling component and a project control component.

19. The project scheduling component should have the following general capabilities:

- An activity-oriented logic network feature to determine critical dates,

- the ability to schedule resources and compute associated costs,

- the ability to project cost trends over time, and

- the ability to report this information as required.

20. The project control component should have the following general capabilities:

- The ability to monitor actual information relative to scheduled estimates,

- an audit trail feature for tracking changes to the approved schedules,

- a suspense monitoring system for managing critical actions,

- a feature for scheduling the work of individuals assigned to the project,

- the ability to report this information as required.

21. Most commercially available "Project Management" software packages are in reality project scheduling packages, while project control systems are generally locally produced systems built upon a relational database. The system which satisfies the LCPM needs would have both capabilities.

22. In addition to the above functional criteria, the system should also have the following technical features:

- interacts with the user in a friendly manner,

- performs internal functions without user downtime,

- ensures retention of error-free data,

- prevents unauthorized access,

- functions on an open DBMS architecture,

- functions identically on multiple operating systems,

- determines early and late start dates using ASAP or ALAP logic, 
- links resources to a project from a central pool,

- performs ad hoc reporting from the database,

- tolerates individual project management innovation to the maximum extent possible,

- has the ability to incorporate a Corps standard work break down structure (WBS) and organizational break down structure (OBS),

- has the ability to incorporate a Corps standard milestone code structure that would indicate dates required on standard reports,

- has the ability to incorporate a Corps standard method of system use so labor hours can be captured successfully.

23. The task group also listed some assumptions for the hardware and software environment in the field offices during the short- and long-term time frames. The short-term assumptions include:

a. All existing Corps stovepipe systems will remain in place and can be used to input data into the preferred software package.

b. The FOAs have existing microcomputers and can obtain additional machines with relative ease. The FOAs do not have existing minicomputers or mainframes with excess capacity and cannot immediately obtain them even if the project management software could be made available to run on these platforms.

c. A Corporate Database System will not be available initially to satisfy the LCPM and other mandatory information needs.

d. The frequency of actual data input will be determined by the FOA consistent with the data being gathered in the stovepipe systems.

e. A network scheduling capability is needed at all operating levels. Each FOA may determine to what level of the organization below IPM/TPM they wish to implement. 
f. Network activity data are provided to the project managers by the functional elements, and actual data come from both the standard and stovepipe systems.

g. The LCPM software will interface with Corps stovepipe systems and with other systems as required.

24. In addition to the above assumptions, the following were assumed to happen in about 2 to 3 years:

a. The redesigned F\&A system will be complete. However, some stovepipe systems will exist such as SAACONS, ACPERS, and REMIS.

b. The FOAs will have minicomputers or mainframes through the CEAP program allowing the development of corporate databases, if necessary, and the porting of their PC-based project management system to the minicomputer or mainframe.

25. The task group developed a philosophy on LCPM implementation at the district level to aid in the definition of requirements and evaluate the software systems. This is provided in Appendix C. 


\section{LCPM REPORTING REQUIREMENTS}

MANDATORY REQUIREMENTS - The reports specified by Initiative 88 are required in both form and content. These requirements, found in EC 1110-2-536, are shown below along with the agency responsible for preparing the report, the agencies that use the report, and the data source for the information.

PROJECT REPORTS REQUIRED BY EC 1110-2-536

Title of Report

Weekly Project Manpower Rpt

Project Sch \& Cost Change Rpt

Monthly Cost Control Change $\mathrm{Rpt}$

Project Monitoring Rpt

Monthly Management Rpt

Continuous Project "S" Curve Rpt

Project Review Board Minutes

Division Executive Summary

HQUSACE Highlight Rpt

ENG Form $\quad$ Report Usage

4981-R

4975-R

4976-R

4980-R

4979-R

4973-R

${ }^{*}$ District

Division HQUSACE

${ }^{*}$ District
Division
HQUSACE
OASA

${ }^{*}$ District

Division HQUSACE OASA

${ }^{*}$ District Division

*Division HQUSACE

${ }^{*} \mathrm{HQUSACE}$
Data Source COEMIS Manual

Manual

EF4975-R COEMIS PRISM AMPRS

PRISM AMPRS OIC

COEMIS PRISM AMPRS Network

COEMIS PRISM AMPRS Network

Narrative

Narrative

Narrative

* Organization responsible for preparing report. 


\section{Table V.2}

\section{OTHER MANDATORY PROJECT MANAGEMENT REPORTING REQUIREMENTS}

The reports specified by higher authority other than those in Initiative 88 are required in both form and content. These requirements are shown below along with the agency responsible for preparing the report, the agencies that use the report, and the data source for the information.

Title of Report

Detailed Project Sch of Funds

Project Cost Estimate

Study Cost Estimate

Cost Rpt by Appropriation \& Division

Summary Cost Rpt by Division

Status Obligations \& Expenditures

Appropriations \& Work Allowances

FY Cost-Budget Summary

Data for Testifying Officers

DTO Justification Sheet

\section{ENG Form}

PB-2A

PB-3

PB-6

FB-4

FB-5

2101

3011A

3018B

DTO

DTO
Report Usage

*LCPM

PMO,Div, HQUSACE

${ }^{*} \mathrm{LCPM}$ PMO,Div

*PD

Div

*PMO

District

*PMO

District

*PMO

District

*DC

Dist,Div, HQUSACE

*DC

Div, HQUSACE

${ }^{*}$ LCPM

PMO,Div

*LCPM

PMO,Div, HQUSACE, Congr

\section{Data Source}

Dist Sch $\mathrm{CD}, \mathrm{ED}, \mathrm{OD}$, RE

Design Memo

PD,ED,RE

COEMIS

F\&A

COEMIS

F\&A

3011A

COEMIS

F\&A

COEMIS

F\&A

PB-3,PB-2A

PB-2A

* Organization responsible for preparing report. 


\section{DETAILED CAPABILITIES/CRITERIA}

\section{A. Networking Capabilities}

\section{Capability}

Interactive Access to Data

Importance: 1

Loop Detection

Importance: 1

Multiple Calendars

Importance: 1

7-Day Weeks.

Multiple Start and Finish Activities Importance: 1

Network Methodology

Importance: 1

Schedule Analysis

Importance: 1

What if Analysis

Importance: 1

Work Break Down Structures

(Forms 4979 and 4981)

Importance: 1

Logic Drawing

Importance: 2

Minimum Working Unit Time

Importance: 3
Description

Ability to Interactively Review and Edit Selective Activity Data in a Tabular

Format.

Loop Detection of Logic Network.

Activities and Resources Scheduled Based on a Combination of 5-, 6-, or

Ability to Accommodate Multiple Start and Finish Activities.

Arrow (ADM) and/or Precedence (PDM) Notation Acceptable. A System with Both Capabilities is Preferred.

Ability to Establish Target Start/Finish Dates and Compute Intermediate Activity Dates Based on Dependencies. (Backward Scheduling, Resource Limited Scheduling, Time Limited Scheduling).

Support What if Analysis for All Resources.

Ability to Define a Hierarchy of Work Items Within the Project.

Ability to Create and Modify the Logic Drawing on the Screen (Interactive Network Editor).

System Allows the Minimum Activity Time Unit Scheduled as 1 Day and Minimum Resource Time Unit as 1 Hour. 


\section{B. Reporting Capabilities}

Capability

Ad-hoc Query \& Computation

Importance: 1

Automatic Spreading of Resources

Over Time

(Form 2101)

Importance: 1

Cost Trend Analysis

Importance: 1

Earned Value Reporting

Importance: 1

Gantt Charts

Importance: 1

Graphical Text Reporting

Importance: 1

Logic Drawing

Importance: 1

On Screen Reports

Importance: 1

Physical Percent Complete Reporting

Importance: 1

Query System

Importance: 1

Report Flexibility

Importance: 1

Reporting Time Frames

(Forms 2101 and PB-2A)

Importance: 1

\section{Description}

Ability for the User to Query the Data Contained in the System and Use it to Perform Basic Computations (e.g., Percent E\&D Based on Construction Costs) and Produce Reports. Ability to Perform Exception Reporting and Suspense Reporting.

The Ability to Spread Resources/Costs Over User Defined Time Periods to Accomplish Obligations and Expenditures.

Ability to Develop Cost Trend Analysis by Features and Project Types to Produce "S" Curve Type Data.

Ability to Compare Scheduled Progress to Actual Progress and Report Earned Value.

Ability to Produce Gantt Chart (Bar Charts) from the Activity Information.

Ability to Automatically Note Critical Dates and Customized Text on the Network Logic or Gantt Chart.

Ability to Generate a Network Logic Drawing from Activity Information.

Ability to View and Edit Reports on the Screen.

System to Provide for Manual Input Physical Progress of Activities.

Ability to Support Ad hoc and Structured Queries of Activity and Resource Information.

Ability to Generate User-Defined Reports Within the Software.

Ability to Establish Reporting Time Frames by FY, Qtr, Month, Day. 
Roll-Up Capabilities Importance: 1

Tracking Progress

(Form 4976)

Importance: 1

Change Tracking

(Form 4975)

Importance: 2

Computational Capabilities

(Forms 4980 and 4979)

Importance: 2

Histogram Reporting

Importance: 2

Graphic Displays

Importance: 3
Description (Continued)

Ability to Roll-Up Resources by Organization and/or Activities to Managerial Interest Levels (e.g., by Division or by Appropriation, etc.).

Ability to Compare Baseline, Revised, and the Scheduled vs. Actual Progress of Activities.

Ability to Automate the Sequential Change Request Numbering.

\begin{abstract}
Ability to Perform Group Costs as Specified by the User (Resource or Work Break Down Structures, etc.) and Perform Mathematical Operations on the Totals.
\end{abstract}

Ability to Obtain Histogram Reporting from Network Data.

Ability to Produce Pie, Line, and Bar Charts. 


\section{Resource Capabilities}

\section{Capability}

Manner Codes

(Form 4979)

Importance: 1

Organizational Break Down Structure Importance: 1

\section{Resource Distribution}

Importance: 1

Resource Leveling

Importance: 1

Fixed/Variable Resources

Importance: 3

Individual Scheduling

Importance: 3

\section{Description}

Ability to Identify Resources by Specific Categories (Work Done by Others, In-House Hired Labor, etc.).

Ability to Establish Resources by Organizational Element, by Position Classification, and by Individual and Apply Them in the Form of Manpower, Dollars, and Time.

Ability to Prorate Resource Usage Over Time.

Ability to Optimize Resource Utilization Across All Projects.

Ability to Establish Variable Resource Levels.

Ability to Schedule Individuals Assigned to Each Activity by Name. 
D. Interface Capabilities

\section{Capability}

Interface with Corps Standard Systems Importance: 1

Project Funds Status

Importance: 1

Word Processing

Importance: 1

Access to Non-network Data Importance: 2

Compatible File Formats Importance: 4

\section{Description}

System to Interface with Corps Standard Systems. The COEMIS F\&A System is Required, Others such as AMPRS, PRISM, SAACONS, REMIS, and CACES, etc., are Required Within 12 Months after Implementation.

Ability to Obtain Project Funds Status for Monitoring Obligations and Expenditures.

System Must be Able to Link/Access Word Processing Software.

Ability to Access Data Contained in Other Databases for Use in Report Preparation (e.g., Cost Estimates Based on Code of Accounts).

System Must be Able to Import from and Export to dBase and ASCII Files. It Would be Desirable if the System Could Also Interface with ORACLE. 


\section{E. Other Capabilities}

\section{Capability}

Ability to Define Project Attributes (Forms 4979 and 4981)

Importance: 1

Customization of the Database

Importance: 1

Database Oriented

Importance: 1

Documentation/Support

Importance: 1

LAN Environment

Importance: 1

User Interface

Importance: 1

Flexible Data Input

Importance: 2

Mini/Mainframe Environment

Importance: 2

Modifications \& Claims Tracking

Importance: 2

Project Changes System

(Form 4975)

Importance: 2

Provide an Audit Trail

Importance: 2

Risk Analysis

Importance: 3

Security

Importance: 3
Description

Ability to Define General Project Descriptions such as Name of Project, District, Division, etc., for Use in Heading Information on Reports.

Ability to Add User-Defined Data Fields.

The System Should Run Directly Within a Relational Database System.

The System Must Be Well Documented and Supported by a Technical Staff Available to Answer User Questions.

The Ability to Operate on a Local Area Network.

The System Should Have a Logical, Easy to Understand User Interface.

The Ability of the User to Create Custom Input Screens.

The Ability for the System to Operate in a Mini/Mainframe Environment.

System to Provide for Tracking Project Claims and Modification.

Ability to Store Changes to the Project in in a File with Network Interface.

System to Provide an Audit Trail of Changes Made to the Schedule Activities and Resources.

System to Provide Risk Analysis.

The Ability to Specify Who has the Authority to Control Reading, Writing, Changing, and Deleting Project Data. 


\section{Software Survey}

26. A survey of commercially available software for project management was performed to determine the most likely vendors who could satisfy the task group criteria. Appendix D contains a list of the software and vendors considered.

27. Six vendors were selected as candidates for review by the task group. A list of capabilities to be demonstrated was sent to the candidate vendors several working days prior to the visit by the task group. These demonstration criteria are contained in Appendix E. All vendors attempted to show that their software could meet the criteria while deviating to dwell on the individual strengths of their software.

28. The vendors visited by the task group and their products were:

Welcom Software Technology, Houston, TX (OPEN PLAN)

Metier Management Systems, Houston, TX (ARTEMIS)

Symantec, Nevado, CA (TIMELINE)

Bechtel Software, Gaithersburg, MD (SYNERGY)

AGS Management Systems, King of Prussia, PA (WINGS)

Primavera Systems Inc., Bala Cynwyd, PA (PRIMAVERA PROJECT PLANNER)

29. The software review was conducted $7-10$ March 89 in the respective vendors' facilities. 


\section{Findings}

30. Software is currently available on the commercial market that can satisfy the requirements of LCPM. The software systems reviewed by the team offered a range of capabilities from a basic planning and scheduling tool to a comprehensive planning, scheduling, monitoring, and controlling tool with a large integrated database. One vendor even offered several modules including a cost construction estimating package. Each software package has advantages and disadvantages for working in the Corps environment; however, each one could be utilized by a district with differing degrees of effort. All of the packages would allow for a progression to larger and broader systems in the future with minimal loss of effort. Individual product reviews are included in Appendix F.

31. Two factors did stand out in the review. One was the flexibility of some products allowing the user to alter the database, the input screens, and the reports obtained from the database. The second factor was the diversity of databases used by the systems. One software package used dBase III + which would tie into databases that already exist in many districts. The other database used was ORACLE. Even though ORACLE is currently being used in only a very few locations, it may well become the standard in the future. While dBase III + and ORACLE are general purpose relational database management systems, several vendors use a special purpose project database system.

\section{PRISM and AMPERS}

32. The task group also looked at using PRISM and AMPERS as LCPM tools. Those findings are summarized in the following paragraphs.

\section{Use of PRISM for LCPM}

33. PRISM development focused on Civil Works construction projects. Although Planning, Operations, Maintenance, and Military Construction projects can 
use PRISM, these generally require "work-around" solutions. PRISM can serve as the data repository with some enhancements. PRISM also has the ability to store several iterations of project data so that a history of changes could be viewed. The PRISM option requires additional investigation, but using PRISM as the total LCPM solution at the IPM/TPM level does not appear to be a viable option.

\section{Use of AMPRS for LCPM}

34. AMPRS does not have any project scheduling capabilities. AMPRS is a repository of information and could serve as the repository of data transmitted from PCs. To handle the information, AMPRS will need to be expanded to store data not currently accommodated. AMPRS as the total LCPM solution at the IPM/TPM level does not appear to be a viable option.

\section{Information Systems Modernization Plan (ISMP) Emphasis}

35. The Corps published ISMP philosophy calls for the development of an integrated database with applications running on this database. The Private Sector Council study criticized this approach. The task group examined both an integrated (see Fig. VII.1) and an interfaced system approach (see Fig. VII.2) for implementation.

\section{Integrated system approach}

36. The advantages of an integrated database are well documented: all users can have access to the necessary data, all data is in a pool of information, a single tool is used to retrieve all information, the data mean the same thing to everyone, singular data storage and singular data entry are provided, etc. These are attractive arguments to the concept of integration of data.

37. The integrated system approach would require all data to reside on a singular platform and all applications to use a simple Relational Database 


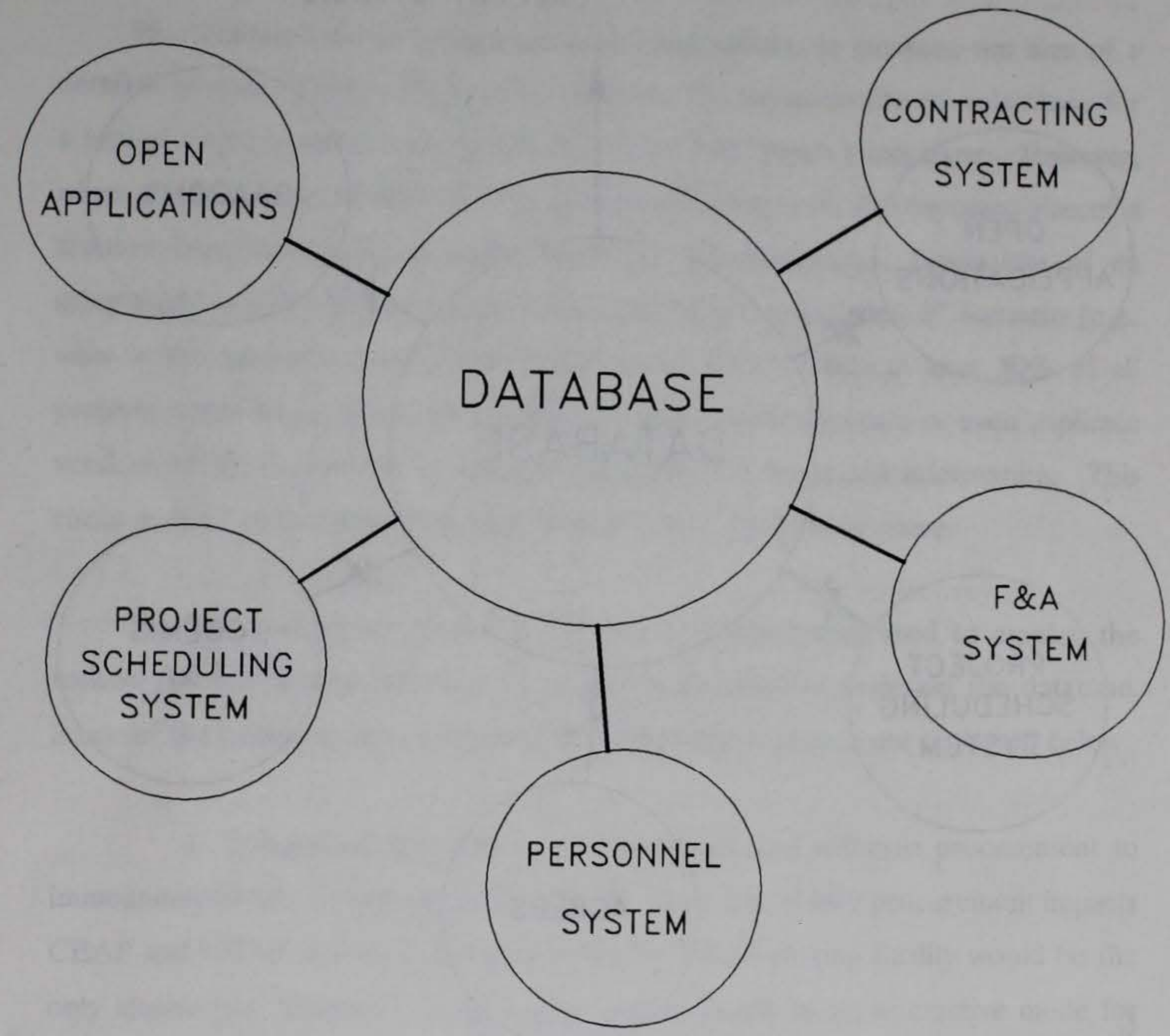

NOTE: ALL APPLICATIONS RUN ON THE SAME RELATIONAL DATABASE MANAGEMENT SYSTEM. TOTAL INTEGRATION MANDATES MINIMAL DATA REDUNDANCY.

PARTIAL INTEGRATION INDICATES DATA SHARING USING BACKGROUND UTILITIES AND INCREASED DATA REDUNDANCY.

FIGURE VII.1. INTEGRATED APPROACH 


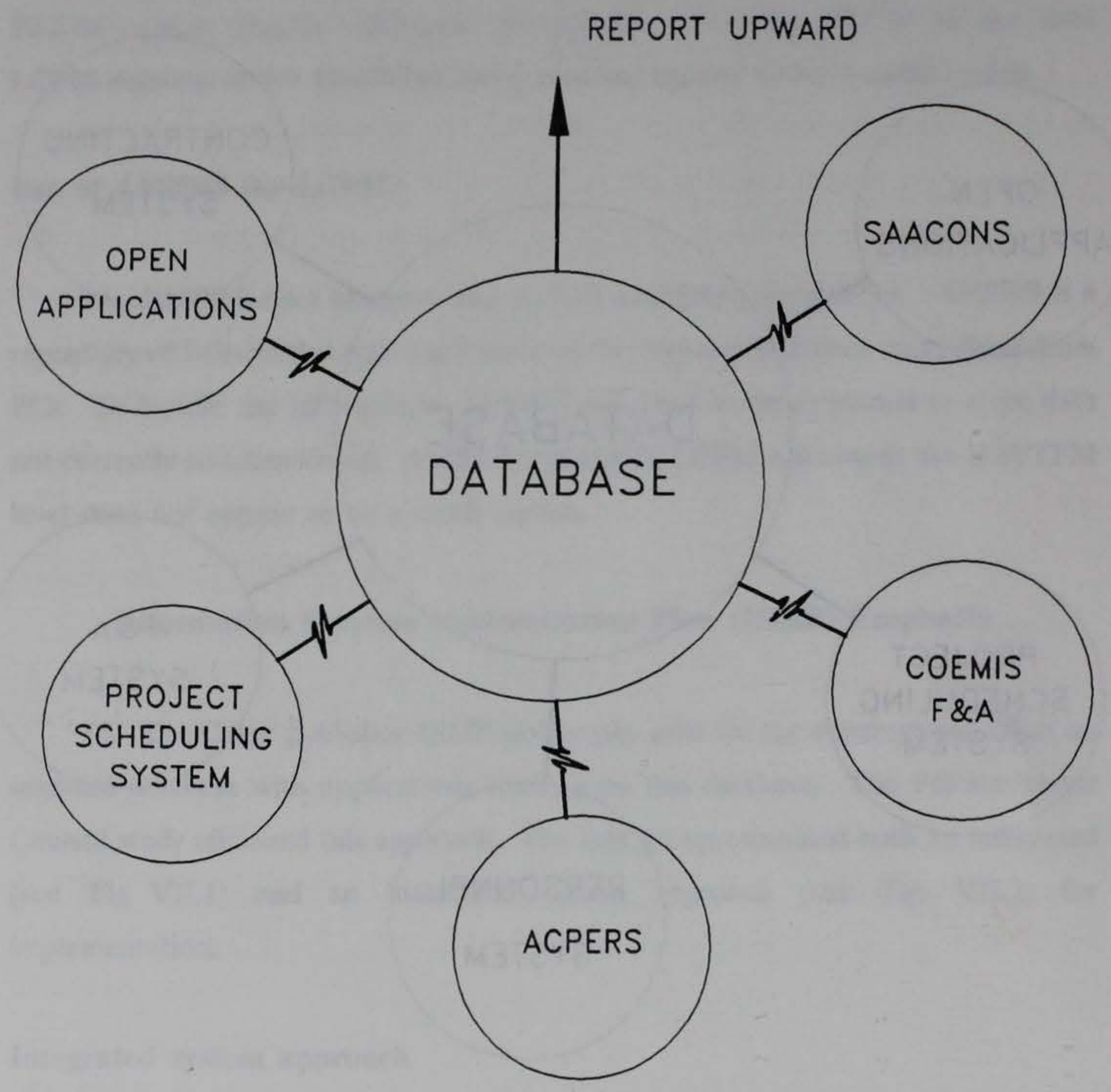

NOTE: APPLICATIONS DO NOT RUN ON THE DATABASE.

THEY ONLY UPLOAD/DOWNLOAD INFORMATION. 
Management System (RDBMS). Total or partial integration as shown in Fig. VII.1 is possible. Of the products reviewed, SYNERGY (by Bechtel Software) embraces the concept of partial integration. No product surveyed had total integration.

38. The task group performed rough calculations to estimate the size of a detailed project database for a typical district. The expected size of a database for a typical single project over the life cycle would be about 1 megabyte. However, when all projects in all districts of a division are integrated, the expected size of a division integrated database could approach 500 megabytes. Limitations of an integrated database become compounded during a frantic "what if" scenario (e.g., what is the project impact if the budget is cut $10 \%$ ?) when at least $50 \%$ of all projects would be involved. The database would contain duplicate or even triplicate versions of project details to answer and justify the requested information. This could expand an integrated division database to 1 gigabyte or more.

39. The cost of integration is not just in the software used to employ the technology, but also in the support personnel required to maintain the database. Some of the problems associated with the integrated approach are discussed below.

a. Integrating data will require hardware and software procurement to immediately handle the additional work load. Since a hardware procurement impacts CEAP and CEAP is a phased implementation, a time-sharing facility would be the only alternative. However, using a time-sharing facility in an interactive mode for this purpose would be so inefficient that it would be impractical. Also, an RDBMS must be procured for the installed hardware. An RDBMS requires more hardware for overhead functions, and the on-line nature of RDBMS data encourages more sophisticated queries. While the database for LCPM does not appear to be very large, neither is it trivial.

b. Support personnel must be readily available for user assistance and system maintenance. It is expensive to train personnel in database administration (DBA) skills with LCPM. Being a critical system, the best people the Corps has must be put in charge of the LCPM database. The Corps does not have extensive 
knowledge of DBA with a relational database in all field offices. The skill level necessary usually requires training and a least 2 years of experience. The risk of database failure is quite high with inexperienced personnel.

c. Database integrity must be continually monitored. Referential integrity (ensuring all data are referentially pure) is the difference between accurate information, lack of information, and misinformation in database queries. Currently there is no system that automates referential integrity; therefore, all application development must check the integrity of related data. In an integrated system, these references would be in several of the tables throughout the database. The lack of referential integrity would cause success of an application to be unlikely.

d. Performance must be continually monitored. An RDBMS may require from three to several hundred times the processing power of either a network or an hierarchical DBMS. The broad range is based on how the RDBMS is structured as opposed to how the comparison system is structured. Performance problems can be corrected by (a) a well-coded system, (b) index usage, and (c) data table definitions and other factors. However, knowledgeable personnel with experience are needed to tune a system if performance begins to degrade.

\section{Interfaced systems approach}

40. The Corps has been operating with interfaced systems since the early days of automation. The disadvantages are well publicized. The advantages are not so well publicized in recent documents. In general, the advantages are solutions to the disadvantages of integration. In the interface approach, the district project managers will have all the necessary tools for daily operation on a PC, and the district could have an integrated database containing project details for total district management reporting. The district level integrated database would be updated by the IPM/TPM periodically. The division would have an integrated database of summary information for division level management reporting. This division summary data would be updated by the district project managers periodically. Finally, HQUSACE 
would have an integrated database of all necessary LCPM data that would be updated from the divisions periodically.

\section{Preferred approach}

41. The task group considers an interfaced database approach as shown in Fig. VII.2 as the best way to implement LCPM in the Corps. Software tools are commercially available to facilitate this approach such that any district could commence implementing LCPM. The commercial software would also allow the districts to move in an orderly progression to larger and broader systems and eventually to a district corporate database. Detailed reviews of the software inspected are contained in Appendix $\mathrm{F}$, and recommendations are made in Section VIII under Implementation Recommendations. 


\section{Conclusions and Recommendations}

\section{Conclusions}

42. The task group concluded that:

a. Software products exist in the commercial market that could be used to satisfy LCPM at all levels of management.

b. LCPM requirements at the district, division, and HQUSACE levels can be satisfied by providing report extracts from the IPM/TPM micro systems.

c. A micro-based project management system consisting of a project scheduler and a DBMS must be identified as part of a recommended system to be used by the IPM/TPM. This would save money in developing interfaces with stovepipe systems such as COEMIS F\&A, PRISM, and AMPRS. However, the FOAs should be allowed to use any project scheduling system below the IPM/TPM level.

\section{Recommendations}

43. The task group's recommendations are divided into two parts: general recommendations that apply regardless of the implementation strategy taken by USACE, and recommendations on how to implement LCPM using commercially available software.

\section{General recommendations}

44. General recommendations include:

a. Select a "preferred" project networking system that would complement the data collection requirement for use by the IPM/TPM. A preferred system is a 
system that is well supported but is not necessarily a standard. Experience with engineering software indicates that successful standards evolve rather than being imposed. A well-supported preferred system is likely to become a defacto standard eventually. This recommendation is made due to the economies of scale associated with common software development. In addition, the common system would promote the movement toward electronic project reporting.

b. Standardize the LCPM reporting database structures from USACE to the district level. This should be done with field input through a task group.

c. Develop a standard work break down structure (WBS) and an organization break down structure (OBS). These standards are essential within a district in order to roll up projects and evaluate resources. They are also essential for a division if they plan to roll up projects from several districts, and for HQUSACE if they desire to roll up all work within the Corps. This effort should be done with field input through a task group.

d. LCPM and project management systems need accurate and timely finance and accounting information to be useful. The current COEMIS F\&A system does not meet this requirement. It is recommended that a new F\&A system that meets the needs of not only the Comptroller but also the resource and project managers be procured or developed as soon as possible. As part of the COEMIS F\&A redesign effort, a study similar to the one undertaken here should be performed (if not already done) to ascertain whether commercial F\&A systems are available to meet the Corps' needs. This could hasten the process.

e. Establish a Center for Computer-Aided Project Management (CCAPM) in the Corps similar to the Computer-Aided Design and Drafting (CADD) Center at the Waterways Experiment Station. The Center, like the CADD Center, should be field-driven and should become the focal point for fostering project management activities in the Corps. The Center would be the working arm for the HQ Program Manager for LCPM. The Center should be small, staffed by experienced engineers and computer scientists. The CCAPM would strengthen the concept of HQ 
providing direction and leaving the execution to the field. The CCAPM would work under the direction of a Field Advisory Group (similar to the CADD Center). This advisory group, consisting of field office and HQ personnel, would be selected by the HQ Program Manager for LCPM. Functions of the CCAPM would include:

(1) Select a "preferred" project management system(s) based on the implementation recommendations described below and assist with procurement.

(2) Form field task groups to standardize data structures at all levels and to develop standard WBS and OBS.

(3) Become a catalyst for field offices to exchange requirements and expertise on project management.

(4) Facilitate training of engineers and managers in project management. The task group feels that there is an urgent need to train engineers in the field offices on the concepts of LCPM and in the use of project management software tools.

(5) Provide guidance for exchanging data between the stovepipe systems and the project management database to minimize the problems the FOAs might encounter.

(6) Identify the required interfaces for customizing the recommended project management system software.

(7) Distribute centrally developed interface programs as well as other programs developed by various districts to facilitate managing and executing LCPM tasks.

(8) Use district resources as much as possible to accomplish tasks. 
f. Further investigate the role of PRISM/AMPRS in the environment where project scheduling will be done using a commercial software system.

g. During CEAP pilot testing consider the impact of CEAP and the redesigned F\&A system on the recommendations. Examples of impacts are: possible changes from one RDBMS to another, migration from PC file servers to minicomputers/mainframes, integration of data in corporate databases (if available), etc. Changes to a recommended micro-based project management system to allow porting of the system to a minicomputer or mainframe should also be identified during the CEAP pilot test period.

\section{Implementation recommendations}

45. The task group recommends an implementation strategy using commercially available software and an interfaced approach. Under this strategy data at all levels of management will be kept at a manageable level. The critical success factor is that all levels, HQUSACE down to district management, must accommodate the next higher level in data transmitted, and the higher level must decide what data are needed for its level of management. The definition of data required for management at HQUSACE must be defined first so that subordinate offices can define their data requirements. Specific types of software for each level and aspect of project management is discussed below.

a. Project Planning \& Scheduling. The task group recommends implementing planning and scheduling functions for the IPM/TPM and resource manager on a PC. The tools available on the market allow for quick and accurate development of plans and schedules. The specific tool viewed by the task group that best suited this purpose was Timeline by Symantec. Other tools exist and all tools viewed by the task group could perform planning and scheduling. The Timeline class of products would be limited to a planning and scheduling role. The task group is not recommending Timeline as the only solution, but only as the class of software that provides a solution. 
b. Project Monitoring \& Control. The task group recommends implementing monitoring and control functions in a rigorous PC software package like Open Plan by Welcom Software or Project Planner by Primavera. These packages offer in-depth analysis and graphical capabilities. Open Plan is more flexible since it is based on dBase III + , whereas Project Planner's graphical reporting is by far the best and is well suited for presentation development. Open Plan provides greatest flexibility for user modification of data entry and textual reporting. Project Planner provides greatest flexibility for graphical reporting. These packages or one like them appears to provide the IPM/TPM the majority of tools necessary to perform data-related work. Additional tools would be necessary to handle Congressional, Corps-specific, and manager-specific efforts and to summarize data for transmittal to the summary databases. This solution allows the IPM/TPM to determine the software most useful for them and have a data transfer utility written to move data from the PC software to the summary district database. Again, the task group is not recommending a specific software but rather the class of software.

c. Project Summarization. The task group recommends implementing the provision of summary information for district use in a standard relational database management system (e.g., dBase III+, dBase IV, FoxBase 2.1, Oracle). The major purpose of this repository is to collect all project summary data from the IPM/TPM and hold it for management reporting. It would be the purpose of the enterprise (e.g., district) managing the repository to determine the data elements required for storage and the detail necessary. Due to the concept of LCPM, HQUSACE should develop the data requirements needed for management prior to the division offices developing their own requirements. Similarly, the division offices should develop their requirements prior to the district developing their requirements. The data would be electronically transmitted from the districts up to HQUSACE through the divisions.

46. Implementation using the interface approach reduces the requirements for a large mainframe to that of a file server role. It allows any platform from a high 
capacity microcomputer to a minicomputer or mainframe to be used. The respective offices (district, division, HQUSACE) could procure necessary hardware based upon their management requirements and funds available. The task group further recommends the interfaced approach to LCPM as the only solution that can be feasibly implemented immediately. This does not preclude the organization from moving to an integrated approach as the necessary hardware becomes available, personnel are trained, and the DBMS software on the market matures to the extent that integration becomes a low-risk alternative.

47. On the contrary, if $\mathrm{HQ}$ desires an integrated approach with all or most applications sharing data with minimal data redundancy, the task group recommends SYNERGY developed by Bechtel Software as the only viable solution. However, this software must be tested in a pilot district and evaluated before further steps are taken. 


\section{APPENDIX A - DEFINITIONS}

1. Activity - An identifiable section of work required to complete a project.

2. Actual - Historical data of time, resource, and money consumed in work.

3. Arrow Diagramming Method (ADM) - A method that identifies an activity using $\mathrm{I}$ and $\mathrm{J}$ nodes. Network logic is defined by identifying events as nodes and each activity occurs between two events.

4. Baseline - The schedule and related data approved by authorities responsible for the project.

5. Current - The schedule and related data identified as the most recently approved plan for project execution.

6. Database Management Based Reporting System - A component of the Project Management System (PMS) that provides both a database for the collection of data from the PMS and the Corps stovepipe systems, and manual input and a report generator for preparing both mandatory and desirable project reports.

7. DBA - Data Base Administrator.

8. Early Start Data (ES) - The earliest date an activity can begin.

9. Early Finish Data (EF) - The earliest date an activity can be expected to be complete.

10. Free Float (FF) - The amount of time an activity can slip without affecting successor activities.

11. FOA - Field Operating Agency. 
12. IPM - Independent Project Manager.

13. LCPM - Life Cycle Project Management. The management approach used by the Corps of Engineers to accomplish its project on schedule and within budget through the use of Independent Project Managers and Team Project Managers.

14. Late Start Date (LS) - The latest date an activity should begin.

15. Late Finish Date (LF) - The latest date an activity should be completed.

16. Network - A combination of activities and the relationships between the activities. Allows for ADM or precedence diagramming method (PDM).

17. Network Analysis - The computation of dates (ES, LS, EF, LF) and slack (FF, TF) for each activity or task within a network.

18. PC - Personal (micro) Computer.

19. Precedence Diagramming Method (PDM) - A method that identifies an activity with a unique code. Network logic is defined by identifying the preceding activities or succeeding activities to an individual activity.

20. Project Management System (PMS) - The two-part system used to manage and control the execution of projects at a Corps facility. The project scheduling component provides for detail down to the lowest authorized organizational level. The project control component consists of a database management system with report generator for the preparation of control reports.

21. RDBMS - Relational Database Management System

22. Resource - An entity that when utilized depletes money from available project funds. 
23. Schedule - The analyzed network which provides the management dates of activities.

24. Task - The lowest identified level of work. Several tasks can be performed within an activity.

25. Total Float (TF) - The amount of time an activity can slip without affecting the project late finish date.

26. TPM - Team Project Manager. 


\section{APPENDIX B - REFERENCES}

Baumann, R. E., and Gravenstein, R. 1988. "Recommendation for a Construction Management Information System," prepared for National Aeronautics and Space Administration by Battelle, Washington Operations, Washington, DC.

East, E. W. 1988 (Oct). "Knowledge-Based Approach to Project Scheduling System Selection", Journal of Computing in Civil Engineering, Vol 2, No. 4, pp 307-328.

Kerzner, H. 1984. Project Management: A Systems Approach to Planning, Scheduling and Controlling, 2nd ed., Van Nostrand Reinhold Co., New York.

Moder, J. J., Phillips, C. R., and Davis, E. W. 1983. Project Management with CPM, PERT and Precedence Diagramming, 3rd ed, Van Nostrand Reinhold Co., New York.

Personal Communication. Bob Thomas and David Pence, February 1989, Engineer Automation Support Activity.

Personal Communication. Bobbi Schwendig and staff, February 1989, Idaho National Engineering Laboratory.

Private Sector Council. 1989 (Feb). "Evaluation of Management Information System Redesign by the Corps of Engineers."

US Army Construction Engineering Laboratory. 1988. "Project Management System Data Exchange Workshop," Champaign, IL.

US Army Corps of Engineers. 1988 (Jun). "Project Management System," EC 1110-2-536, Washington, DC.

US Army Corps of Engineers. 1989. "Life Cycle Project Management STRAP Report," Washington, DC.

US Army Corps of Engineers. 1989. "Life Cycle Project Management Off-theShelf Software Survey," Washington, DC.

US Army Engineer Division, Lower Mississippi Valley. 1988. "Report of an LMVD Committee to Investigate Division-Wide Computer-Based Project Management Systems and Proposed Changes to Standardize ADP Workcodes," Vicksburg, MS.

Walsh, K. J. 1988 (Jan). "Road to Effective Project Management," Journal of Management in Engineering, Vol 4, No. 1, pp 65-74. 


\section{APPENDIX C - LCPM PHILOSOPHY}

C1. There are several aspects of the Corps' mission that are different from those of a commercial enterprise construction company. As such, the philosophy of LCPM in the Corps must first be established before automated systems are selected for practicing LCPM. Some of these issues are outlined in this section.

\section{Functional Responsibilities}

C2. District management personnel are grouped as resource managers and independent project managers (IPM).

\section{Resource managers}

C3. The resource manager has the responsibility to accomplish the work as well as the identification and documentation of any deviations in the scope of work, schedule, budget, and project cost. This responsibility requires access to the network including all planned and actual data from which they can monitor and evaluate the progress of their own work. This of course is not done in isolation but in cooperation with the entire team and the project manager.

\section{Independent project managers}

C4. The IPM/TPM has the responsibility for planning, scheduling, monitoring, and controlling the project from a district perspective as well as identifying and documenting any deviations in the scope of work, schedule, budget, and project cost. The documentation of any change to the baseline schedule, resources, and cost should be attached to the activity generating the change. The documentation would also be placed in a database so that there is a clear audit trail of all changes with accumulative impacts. 


\section{Project Management Philosophy}

C5. The team believes that district LCPM level should commence with initiation of the reconnaissance report instead of waiting until the feasibility report is completed. This creates a "cradle to grave" management of the project (see Fig. C.1). The cost estimating, project planning, and project scheduling phases could be handled by commercially available software. It is assumed that the IPM/TPM would use this software. The project monitoring and project control phases are comparatively long duration phases which would require more rigorous software for the daily chores. These too appear to be available commercially.

C6. A Corps IPM/TPM is responsible for control of an assigned project. The IPM/TPM maintains the official baseline network as -well as the other official schedules such as current and projected. No one other than the IPM/TPM can change the schedules or associated information. Other data required by the IPM/TPM is extracted from the various stovepipe systems and placed in the project database. The information flow from the district upward is shown in Fig. C.2. The requirement for detail will decrease as the information flows upward as shown in Fig. C.3.

C7. The IPM/TPM utilizing the network schedule and associated information prepares all reports required internal to the district and for submittal to higher authority. The management of a project should be composed of estimating, planning, scheduling, monitoring, and control. For the purposes of this study, these tasks are defined in the following paragraphs.

\section{Project estimating}

C8. The total cost of the project consists of Engineering and Design (E\&D) cost to get a project to the construction stage and the construction cost. E\&D costs are derived from the IPM/TPM system. The construction cost would be derived from a program such as CACES that will be interfaced with the IPM/TPM system. 


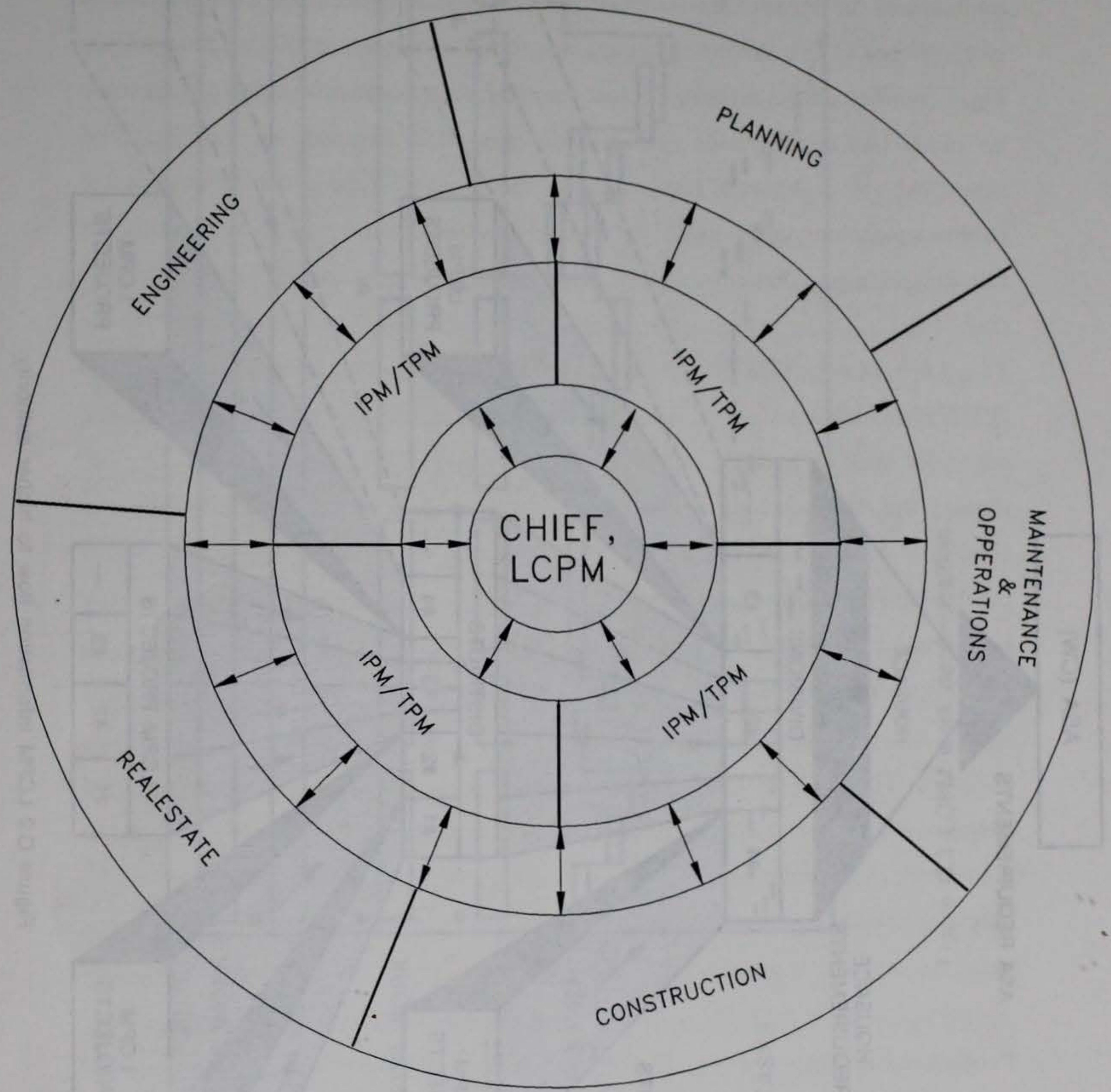

DISTRICT LCPM INFORMATION FLOW

FIGURE C.1 


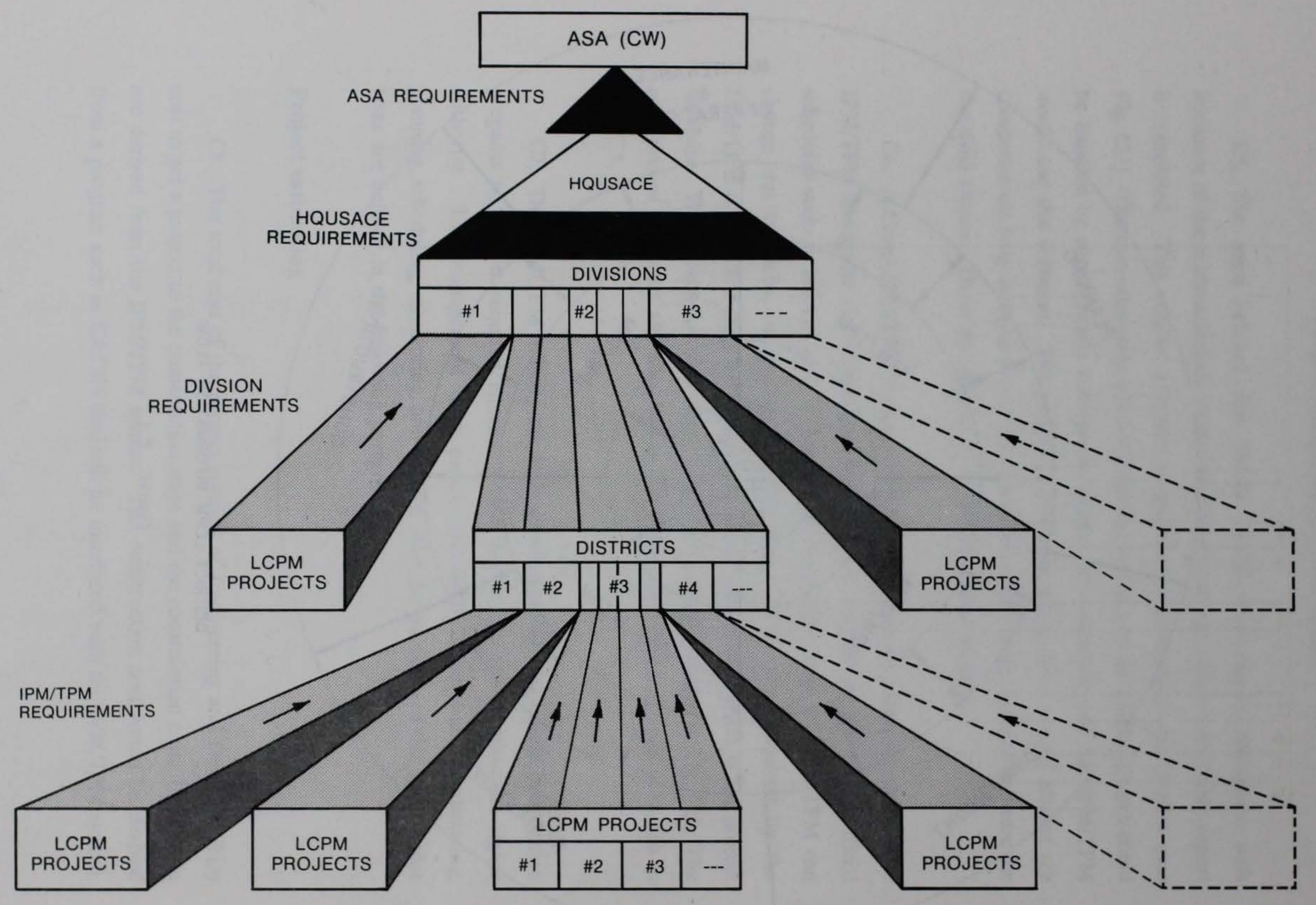

Figure C.2 LCPM information flow to higher authority 


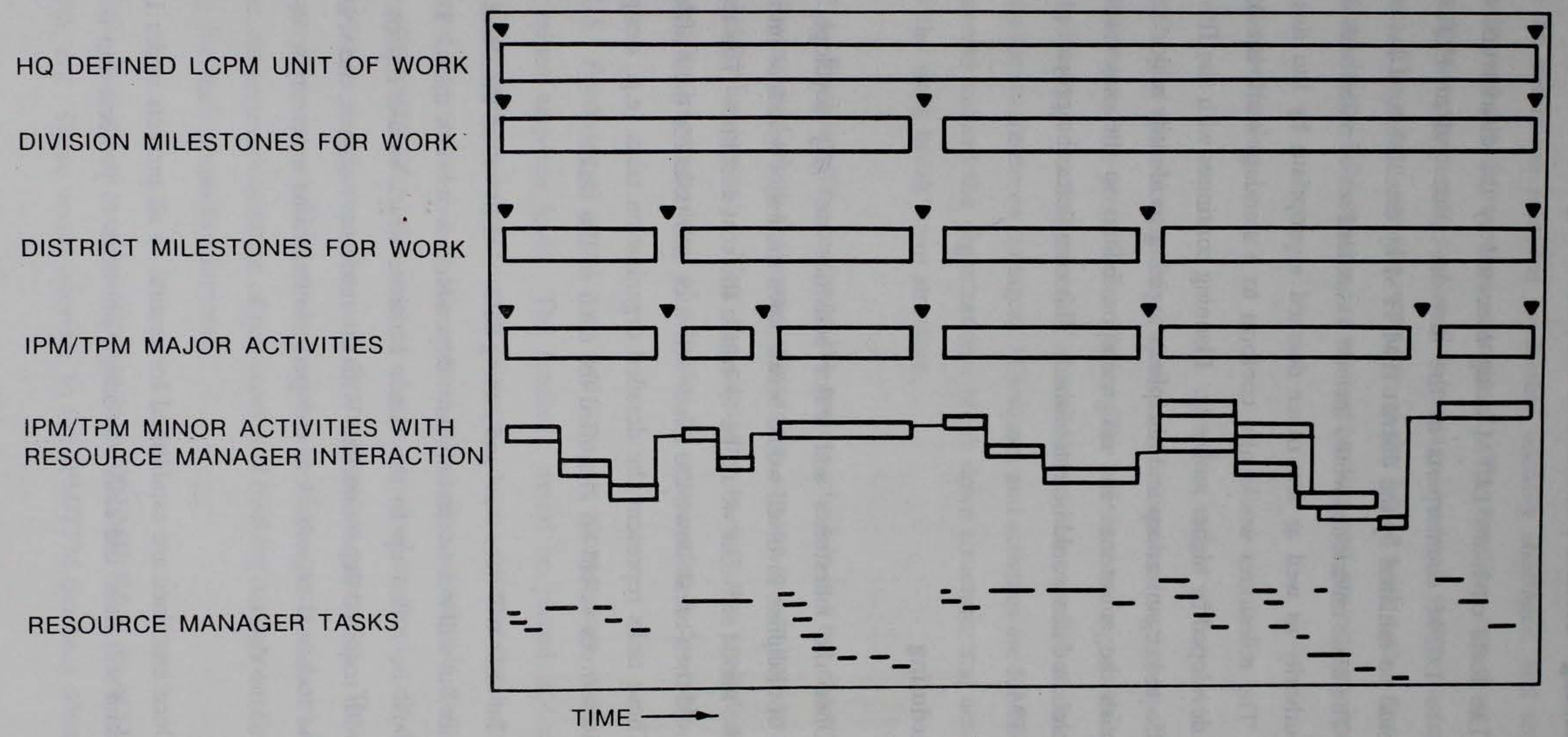

Figure C.3 LCPM work decomposition 


\section{Project planning}

C9. The team envisions LCPM being executed by the district offices who then report to LCPM counterparts in the division office and at HQUSACE. Planning would be initiated by the district IPM/TPM by establishing a list of basic milestones. The basic milestones would include a standard set of milestones defined by higher authority as well as any other deemed appropriate by the district or IPM/TPM. The milestones would also conform to a standard work break down structure as developed by higher authority. Planning continues with the IPM/TPM getting all affected organizations and disciplines together to identify major activities that accomplish the milestones and assign responsibilities to the major activities. Target completion dates would be established. This completes the project planning phase of LCPM.

\section{Project scheduling}

C10. Once the milestones and major activities are fully developed, each organization or discipline involved would break down the major activities into minor activities. The minor activities would be to create the cost accounts. The resource managers would then break down the minor activities into tasks for their office (see Fig. C.3). These tasks represent the detailed organization tasks (e.g., design task drawings). Resources would be identified for each of the tasks.

C11. The tasks will have start and ending dates that fit within the dates of the minor activities but will not necessarily have dependencies between them. The task resources would be rolled up to the minor activities which would represent the lowest level with required dependencies. With the resources assigned, the IPM/TPM along with the technical organizations can perform iterations necessary to establish baseline milestone dates.

C12. Once baselines are established for several or all projects under LCPM, the LCPM chief will have the ability to assign priorities to projects and compare 
resource requirements against the pool of available resources. This will allow the district to determine resource availability, identify shortages, and show detailed project impact due to resource restrictions. The baselines can then be approved from a district perspective and used to manage, monitor, and evaluate the project progress. The minor activities would form the list of work codes that need to be established in the F\&A system for cost accounting and project monitoring.

\section{Project monitoring}

C13. The monitoring of project status requires two perspectives. The IPM/TPM views the project as a whole. The resource manager views the project as one of many projects the section is to work on over a period of time. Tasks are primarily for the resource manager. Milestones and activities are for the IPM/TPM. Tasks center around the organizational break down structure, and activities center around the work break down structure.

C14. The capability to display the project schedule in a bar chart format down to the lowest level which the resource managers can use to monitor execution of the work should be present. Also, the capability to sort the project schedule and associated bar charts by level of activities by organization is desirable.

C15. Feedback of actual costs and resource consumption would be provided to the minor activities level. The feedback would be placed in the automated scheduling system to indicate actual progress. Actual data feedback to the tasks is considered impractical due to the amount of detailed actual data that must be fed into the COEMIS F\&A, the amount of time required to input such data, and the difficulty in managing the volume of data and rejects generated. The feedback to the minor activities would be made available to all managers to assist in evaluating progress, monitoring utilization of resources, and tracking cost against the established baseline for their respective interest.

C16. Actual data must be obtained from COEMIS F\&A, SAACONS, REMIS, ACPERS, etc. These would interface to the IPM/TPM database wherein the data 
is periodically uploaded to the LCPM database. The IPM/TPM would extract data from the stovepipe systems as required.

\section{Project control}

C17. For the IPM/TPM to have the ability to control the progress of the project, it is necessary to have summary data to the desired level. With summary data, managers, at all levels, can review progress against the milestones, major or minor activities, or other desired reporting criteria.

C18. Project control entails reassigning resources to activities, reevaluating activity logic, and controlling changes to the project scope. The control of a project is through the management of changes by both the Corps and the contractors. Accurate forecasts of how a change affects project operation are a by-product of accurate change estimates in time and cost. The ability to control cost would be enhanced by increasing the use of direct charges to the project consuming the labor or materials rather than relying on the indirect and overhead charge backs. Increased use of direct charges would provide the project manager with additional cost information.

\section{Summary}

C19. In summary, the IPM/TPM prepares an initial network schedule with broad milestones. The IPM/TPM and resource managers together develop the major and minor activities. Resource managers develop tasks and identify the required resources. Following several iterations, a baseline is established for the schedule, resources, and cost. IPM/TPM utilize the milestones, major activities, and minor activities to evaluate progress. Resource managers utilize tasks to manage the execution of the work. Feedback of actuals to the minor activities is furnished to everyone involved. All changes to the schedule, resources, and cost are documented, reflected in the network schedule, and included in the project database. 


\section{APPENDIX D - LIST OF PROJECT MANAGEMENT SYSTEMS CONSIDERED}

PAC and Wings from AGS Management Systems, Inc.

Advanced Project Workbench from Applied Business Technology

Synergy from Bechtel Software, Inc.

ViewPoint from Computer Aided Management, Inc.

SuperProject Expert and CA-Tellaplan from Computer Associates Intl.

Plantrac from ComputerLine

Artemis from Metier Management Systems, Inc.

N5500 and N1100 from Nichols \& Company

PMS-II from North America MICA

PMS-80 from Pinnell Engineering

Primavera Project Planner from Primavera Systems, Inc.

Project/2 and Quiknet from Project Software \& Development, Inc.

Project Scheduler/4 from Scitor Corp.

Harvard Project Manager from Software Publishing Corp.

PROMIS from Strategic Software Planning, Inc.

Timeline from Symantec Corp.

Vis1on from Systonetics, Inc.

Open Plan from Welcom Software Technology, Corp. 


\section{APPENDIX E - DEMONSTRATION SCENARIO PROVIDED TO VENDORS}

When demonstrating the operation of the software, the following features should be shown to exist and operate in the presented software:

1. Select the beginning month of the fiscal year.

2. Enter resource pool information including resource identification with name, total units available by time, regular hourly rate, overtime rate, organization code, and code denoting hired labor or other type resource.

3. Enter dates in either DD/MM/YY, YY/MM/DD, or DD-MMM-YY format.

4. Define work week calendars that span at least 100 years with holidays.

5. Create calendars for 5-, 6-, and 7-day work weeks as a minimum.

6. Create macros with learn mode supported.

7. Create reports in a batch mode.

8. Support either ADM or PDM or both.

9. Locate loops with Network algorithm.

10. Augment underlying database with user-defined fields.

11. Create an audit trail.

12. Provide security of data by assigned user. 
13. Interface with a minicomputer/mainframe project management system.

14. Execute on a local area network.

15. Create word processing documents.

16. Define ES and EF of zero duration activity.

17. Support resource leveling.

18. Project identification with name, project manager name, project start date, project end date, date of last update, baseline and revised baseline schedule, and user text region.

19. Activities with unique identification, description, duration in hours, days, weeks, or months, calendar used, hammock (or subproject reference), ES, EF, LS, LF, SS (TS), SF (TF), FF, TF, responsible organization, accounting cost code, work break down structure, text to annotate activity information, and physical percent complete.

20. Milestone with unique identification within activity, date of milestone, and description.

21. Resource spread over time - Resource used with unique identification within activity, description, performing organization (performing individual), duration with incremental requirement or total requirement over life of activity or total requirement over duration, organization break down structure, resource used to date, and percent complete.

22. Fixed resource regardless of time - Fixed cost (as in a contract) with unique identification within an activity, description, type of fixed cost (contract, purchase order, etc.), date for beginning cash disbursement, duration, total cost, obligations to date, expenditures to date, commitments to date, disbursed to date, and accrued to date. 
23. Reporting - Ability to:

a. Customize the report headings.

b. Customize the standard reports.

c. Perform ad hoc reporting against the stored data to include user-defined sort and selection, subtotals on sorted fields, report totals, detail reporting, summary reporting, subtotal headings and footings, and intermediate columns derived from math functions on project data. 


\section{APPENDIX F - SUMMARY SOFTWARE REVIEWS}

\section{System Name: OPEN PLAN}

2. Description: Open Plan is available from Welcom Software Technology and runs on IBM compatible PCs and on the DEC VAX under VMS. It operates in either the Arrow Diagramming Method (ADM) or the Precedence Diagramming Method (PDM). GSA Cost $\$ 2,310.00$.

3. General Operation: Open Plan operates from within dBase III+ (or compatibles FOXBASE + and RECITAL in the VAX). The program is written in dBase procedure code (except for the scheduler and query/report writer) and files are stored in dBase format. This allows the user to customize both code and database to local requirements. Other files that are not part of Open Plan may be integrated into the system.

4. Data Entry: The system data is entered through data input screens which can be customized, or a graphical mode which allows the user to see the network logic as it is prepared. Data is also accessible directly through dBase for users who prefer to bypass menus or execute ad hoc queries.

5. Reporting: Open Plan uses the reporting features available in dBase in addition to its own report writer. These features allow for sophisticated customization of both graphical and tabular reports by the user.

6. Comments: Open Plan offers a great deal of flexibility in its adaptability to the Corps environment. The dBase orientation provides a tool that can be interfaced immediately with other district dBase applications. Interfaces with other systems can be readily created through dBase and linked directly to the scheduling system. Multiproject scheduling and summary features are contained in the system, but unless it is used in a multiuser environment, these features will probably not be fully utilized. One option that has real potential is the PRISM import and export routine.

7. Conclusions: Open Plan appears capable of meeting all current LCPM management and reporting requirements. Its dBase orientation means quick acceptance in most district offices and the ability to rapidly create interfaces with existing systems. The Chicago District has already customized Open Plan to produce LCPM reports. 
1. System Name: ARTEMIS

2. Description: ARTEMIS is a commercially available project management software program from METIER, a subsidiary of Lockheed. The program runs on IBM compatible PCs, DEC VAX, and IBM mainframes. It operates in either the Arrow Diagramming Method (ADM) or the Precedence Diagramming Method (PDM). GSA Cost $\$ 6,000.00$ for PC version.

3. General Operation: Artemis operates from within its own relational database system. The program is written in its own Artemis language which allows the user to customize both the code and the database to his own requirements. Other data files may be integrated into the system.

4. Data Entry: The system is fed through user-customized data input screens, or a graphical mode which allows the user to see the network logic as it is prepared. Data is also accessible directly through Artemis' language for users who prefer to bypass menus or execute ad hoc queries.

5. Reporting: ARTEMIS uses the reporting features available in its scheduling package in addition to the customized features available in the Artemis language to produce reports. These features allow for sophisticated customization of both graphical and tabular reports by the user.

6. Comments: The system offers a great deal of flexibility in its adaptability to the Corps environment. The Artemis language seems to have a sophisticated capability although it is different from systems currently in use in the district offices. Interfaces with other systems can created. Multiproject scheduling and summary features are contained in the system, but unless it is used in a multiuser environment, these features will probable not be fully utilized.

7. Conclusions: Artemis appears capable of meeting all current LCPM management and reporting requirements. The database structure has limited ability for customization. 


\section{System Name: TIMELINE}

2. Description: Timeline is a commercially available project management software program from Symantec Corp. The program runs on IBM compatible PCs. It operates in the Precedence Diagramming Method (PDM). Cost $\$ 700.00$ list, $\$ 350.00$ discounted.

3. General Operation: The program is written in the Modula-2 language and allows virtually no customization by the user. It does have a well-developed export routine for sharing files with other systems. An arrangement with Artemis and Welcom Software has been established to allow the sharing of project data between systems. There is no mainframe version of Timeline itself.

4. Data Entry: The system is fed through a combined data input screen and gantt chart. A useful feature of the system allows the schedule to be prepared in an outline form according to a work break down structure. This allows the roll up of detailed activity information in a graphical manner that is useful for managerial level reporting in a simple format. Tabular reporting of costs are also rolled up based on the graphical representation.

5. Reporting: Timeline has a series of reports available. The user can selectively view desired information, but there is no facility to produce customized reports that are not tabular displays of the project data. A graphical representation of the network logic is available on the screen.

6. Comments: The system offers a simple tool which could be used at the lowest levels of the organization to produce schedule and limited resource information. This could be a cost-effective tool since Timeline is generally available for upgrade within most districts due to its availability on the Zenith contract. Timeline is not a database system and does not have any sophisticated customization abilities.

7. Conclusions: Timeline does not appear capable of meeting current LCPM management and reporting requirements. There does appear to be a role for the use of Timeline as a feeder system for a more sophisticated tool. Data would need to be exported from Timeline into another system for analysis of multiproject impacts and the production of sophisticated reports. This would require that the districts standardize on Precedence Notation for scheduling projects. 


\section{System Name: SYNERGY}

2. Description: Synergy is a commercially available project management software program from Bechtel Software. The program runs on IBM compatible PCs and on the DEC VAX. It is a total environment system encompassing not only project scheduling, but also accounting, estimating, resource management, and other modules. The project scheduling module is called PANORAMA and may be operated in either the Arrow Diagramming Method (ADM) or the Precedence Diagramming Method (PDM). Each of 11 modules costs $\$ 2,000$. PANORAMA costs $\$ 5,000$.

3. General Operation: The program operates from within ORACLE. The program is written in ORACLE code, and the files are stored in ORACLE format. This allows the user to customize both the code and the database. Other files that are not part of the system may be integrated into the system. The modules of the system all work together. Individually, the modules are less sophisticated than many others available (the scheduling package has no cost computation capabilities, for example), but the relationship between the modules enhances the total package's performance.

4. Data Entry: The system is fed through user-customized data input screens or a graphical mode which allows the user to see the network logic as it is prepared.

5. Reporting: Synergy uses the reporting features available in its reporting module in addition to limited report preparation ability within PANORAMA. These features allow for sophisticated customization of both graphical and tabular reports by the user. Ad hoc reporting and customized reports can be generated by ORACLE reporting products.

6. Comments: Synergy is not a simple system. The system offers a great deal of flexibility in its adaptability to the Corps environment. The ORACLE orientation provides a tool that can be interfaced with the future plans of the ISMP program to convert the corporate database to ORACLE. Currently, however, ORACLE is not in use in quantity within the district offices. As such, it would take an extraordinary effort to field the system. A system like this could play a part in the Corps' long-term system needs, but current hardware availability problems (CEAP questions) limit its current utility.

7. Conclusions: Synergy does appear capable of meeting all current LCPM management and reporting requirements. The effort associated with fielding a system such as this would certainly take in excess of a year and would involve a dramatic revision of the current way of doing business. This would probably be beneficial to the Corps, but premature at this time. When ORACLE is running in the districts and the systems are modernized, this system should be reexamined. Prior to this product purchase, testing must be conducted at a pilot field office test site. 


\section{System Name: WINGS}

2. Description: Wings is one of the project management systems developed by AGS Management Systems, Inc. The system is available on IBM mainframes, DEC VAX minicomputers, and IBM PC and compatibles. The single user GSA price for the $\mathrm{PC}$ is $\$ 9,500$.

3. General Operation: Since Wings is available on mainframes as well as microcomputers, the PC version retains most of the mainframe look and feel. The system is menu driven. The menus are constructed such that the system can be command driven when the user becomes proficient. The product operates as close as possible on the PC as on the central computer installations. The underlying database is proprietary and the user is not allowed to change the database structure. Customization is available through the vendor. Wings will operate on a LAN. On the LAN, a project can be used by one person at a time.

4. Data Entry: The data entry displays are able to be customized by the user. Mandatory entry fields must be retained on the customized displays. The data is entered in the common field by field approach. The command level allows for quick navigation of the data entry displays rather than facilitating data entry into the database. The product supports a cost-sharing approach to a project. Wings can store costs at the various levels of the work break down structure.

5. Reporting: The reports provided by the product contain limited graphical capabilities. The columnar reports are common to other products. The reports are basically templates that can be applied to various levels of reporting within the work break down structure. Summarization and aggregation of data are supported for display of data by various periods of time within a single report. This feature would support the current format of project reporting.

6. Comments: The product is undergoing development to support full graphical reporting. The product does not have a clean mechanism for project change tracking or resource time blocking. Multiproject reporting is supported with appropriate reports available.

7. Conclusions: The Wings product, with some customization, could be used as an LCPM tool. The currently supported platforms do not include currently installed Corps hardware. It may. be possible for the product to function on a high-speed microcomputer in a LAN environment. 
2. Description: Project Planner is a sophisticated project monitoring system based on the bTrieve product line. The underlying database is usable by the rTrieve and the xTrieve products. GSA Price: $\$ 1,500.00$ (graphics $\$ 900.00$ extra).

3. General Operation: The system is menu controlled with a batch operation if desired. The menus are mainframe oriented and do not fully use the capabilities of a PC. The graphical add-on is impressive and is a definite asset to the product.

4. Data Entry: The data is entered through fixed data entry displays. The menu structure is shallow so the movement between screens is tolerable. The means for quick project planning and scheduling are not evident. The product supports a batch updating capability for input of actual costs.

5. Reporting: The main strength of Project Planner is the graphical capability of the Primavision add-on package. This product truly provides presentation quality graphics. The graphical capabilities exceeded all other reviewed packages. Currently formatted LCPM reports are not readily offered in the package. Since the software uses the bTrieve data storage modules, ad hoc reporting is theoretically possible. However, personnel need to be trained on bTrieve which is not a common database language. Several districts are currently using the Primavera products for LCPM.

6. Comments: Project Planner is a menu-controlled system with no export capability. The user interface will require training as the required entry is not always self-evident. The full project management suite of products would include Project Planner, Parade, and Finest Hour (for hourly scheduling). Integration on the PC is through a vendor-supplied menu system. Multiple project linking is by a merge capability. This would increase the required disk capacity if many merges were required. Merged projects would tend to be those that were enormous in scope. The reports allow for the comparison of two schedules at a time.

7. Conclusions: This product supports most of the criteria requested by the team. The graphics are impressive. However, the system is somewhat inflexible for developing customized reports. 


\section{System Name: PRISM}

2. Description: PRISM is a USACE-wide project and resource scheduling system utilizing the Arrow Diagramming Method (ADM) that runs on Honeywell computers at the divisions. The system allows for the scheduling of all projects (civil and military). The system interfaces with other COEMIS elements (personnel and F\&A most significantly) and is designed to compute resource requirements for individual projects as well as assessing the impact of the entire district's work load on the capabilities of the district. The system was designed and maintained by the Programs Management offices, and the primary focus has been on the ability to summarize information for upward reporting purposes.

3. General Operation: The system is menu driven with remote communications to a Honeywell computer running in ASCII character/line mode transmission. Reports are batch oriented. The database is in DM-IV, and the application is written in DM-IV TP and Cobol.

4. Data Entry: The system is fed through an on-line interactive system located on the division Honeywell. The user normally logs on to a TAB-132 terminal and is guided through a series of menus to a data input screen. This is a very slow and laborious process due to both system design and hardware restrictions. Proper coding of activity information allows the system to access other data systems (e.g., actual costs from the F\&A database) and to perform a network analysis to determine activity start and finish dates. Once the data has been input, other menu options allow the user to compute the costs of activities, determine the project schedule, and produce reports. A PC-based package written in micro-focus Cobol is under development which allows the project manager to extract project information to the PC for data entry and then reload it in a batch mode for processing. Many of the reports that the district Programs Management offices are required to maintain and forward to HQUSACE are intended to be extracted automatically from the PRISM database.

5. Reporting: Reporting is limited to the standard reports, locally developed reports, and ad hoc reporting through the LOUIS query system.

6. Comments: The system is "user hostile." The speed of response and the time required to enter and update the data have eliminated the potential benefit to the project manager. There is no current documentation for the user to read when a problem is encountered. Menu selections do not work. Reports, which cannot be run from the menu, require that the user exit the system and run the report from the Honeywell's Job Control Language. The system also has no ability to produce a network logic diagram, a critical tool for the project manager. The system's orientation has been toward roll-up and upward reporting of information at the expense of the project manager who is charged with maintaining the data. PCbased systems have shown project managers that the tools available commercially are much better at meeting their needs than PRISM and that PRISM does not have the ability to accept data generated in other systems. 
7. Conclusions: PC-based systems are generally oriented around a single or small number of projects (the PC is nominally a single user environment). The abilities to look at the effects of multiple concurrent projects on the district as a whole, to level the district's resources over multiple projects, and to interface directly with the F\&A system are features that are easier to manage in a mainframe environment. PRISM could be revised to allow the manager to do the schedule input on the PC with a commercial scheduling package, export the information to PRISM for resource leveling and cross project summary information (to include LCPM reporting), and then extract the information back to the PC for the project manager's use. This approach is workable with current hardware but would require software changes. 


\section{System Name: AMPRS}

2. Description: AMPRS is a USACE-wide database that runs on the Honeywell computers at the divisions and at EASA. The database is made up of selected information on all projects (both civil and military) which will ultimately go into construction. Projects are added to the database at the time that the decision is made to go ahead with the project (usually after the feasibility or letter report). The data stored in the files consist of key dates for the project, cost projections, general project data (location, project manager, contractor, etc.), and a listing of modifications to the construction contract. Local districts have the option of adding new fields to the system for local use in addition to those fields required in upward reporting.

3. General Operation: AMPRS requires a PC, the Division Honeywell computer, and communication with EASA. The system design is concentrated in the reporting of construction project data.

4. Data Entry: The system is fed through a PC-based package written in microfocus Cobol called AMUS which provides a menu-driven routine through which the user can enter data which is batch loaded onto the Honeywell. This data is then extracted back to the PC in ASCII format and transferred via modem to the Honeywell at EASA where it is merged and made available for Corps-wide analysis and HQUSACE information. This is done on a monthly basis.

5. Reporting: Reporting is limited to the standard reports and locally developed reports.

6. Comments: The system advertises itself as the "official" Corps of Engineers information system. Management has generally ignored it and asked for similar information to be produced manually (witness the LCPM reports). It is seen as an unrewarded exercise by most of the people who are required to contribute to the system. The system has no network scheduling abilities; it is strictly a database. The schedule derived information contained in the database must be produced elsewhere and retyped into the database.

7. Conclusions: The manual reporting requirements are largely unworkable. A database system which contains the information from which HQUSACE could extract information of interest would be a convenient solution to this problem. The AMPRS data could be revised to reflect the report requirements (other data would be eliminated). Project managers would manage their schedules on PC-based systems and then extract and summarize the data in a format which could be batch loaded into AMPRS. Care must be taken in this approach to ensure that the information requested can be produced from network data. 